\title{
Novel Luminescent Diazafluorenone Liquid Crystals
}

Korinna Bader, ${ }^{\dagger, \downarrow}$ Rafet Gündemir,,${ }^{\dagger}$, Wolfgang Frey,${ }^{\dagger}$ Philipp Ehni, ${ }^{\dagger}$ Yann Molard,,${ }^{\S}$ Angelika Baro, ${ }^{\dagger}$ and Sabine Laschat*,†,iD

$\dagger$ Institut für Organische Chemie, Universität Stuttgart, Pfaffenwaldring 55, D-70569 Stuttgart, Germany

§Université de Rennes 1 -CNRS UMR 6226 Institut des Sciences Chimiques de Rennes, Avenue du Général Leclerc, 35042 Rennes cedex, France

$¥$ Both coauthors contributed equally to this work.

\begin{abstract}
In this work, the synthesis, X-ray crystal structure analysis, studies on mesomorphism and luminescence spectroscopy of 2,7-diphenyl-4,5-diazafluorenones carrying 2, 4 or 6 peripheral alkoxy side chains of different lengths in the mesogenic unit are reported. The latter was attached to starting 2,7-dibromo-4,5-diazafluoren-9-one via Suzuki cross coupling of the respective 2-(alkoxyphenyl)-tetramethyl-1,2,3-borolane. The liquid crystalline properties were found to depend on both the number of side chains and their lengths. Derivatives with two short alkoxy chains (C6-C8) in the periphery formed nematic (N) and smectic $\mathrm{C}$ $(\mathrm{SmC})$ mesophases while for the higher homologues only $\mathrm{SmC}$ mesophases were observed. Compounds carrying six alkoxy side chains with a minimum length of $\mathrm{C} 8$ assembled into columnar hexagonal phases. Homologues with $\mathrm{C} 14$ and $\mathrm{C} 16$ chain length displayed additionally two columnar rectangular mesophases. Four peripheral alkoxy chains, however, led to the loss of mesomorphism. Crystal structure data of a series of rod-shaped diazafluorenones helped to rationalize their liquid crystalline self-assembly and to understand geometry and thermal stability. Temperature-dependent luminescence spectra of diazafluorenone with two C12 chains revealed aggregation-induced emission (AIE) depending on the supramolecular order of the bulk phase. These studies suggested that AIE requires a lower degree of aggregation as compared to mesophase formation.
\end{abstract}

Keywords: fluorenone, luminescence, crystal structure, mesophases, nematic, smectic, columnar, X-ray diffraction 


\section{- INTRODUCTION}

The self-assembly of rod-like molecules consisting of a bi- or tricyclic rigid core unit and two or more flexible peripheral side chains leads to the formation of liquid crystalline phases (socalled mesophases) with long range orientational order and nanosegregation of immiscible parts. ${ }^{1,2}$ A large variety of rigid rods such as biphenyls, saturated analogues, phenylpyrimidines, naphthalenes, azobenzenes, anthracenes or phenanthrenes have been used for this purpose. Introduction of lateral dipole moments by grafting polar groups to the rod gives tilted phases, e.g., smectic $\mathrm{C}(\mathrm{SmC})$, which are of great practical importance for switching devices. ${ }^{3}$ A very successful SmC promoting group is fluorenone, as was discovered by Sackmann, ${ }^{4}$ Shimizu, ${ }^{5,6}$ Mazepa $^{7}$ and more recent extensive work by Lemieux ${ }^{8-11}$ and Donnio ${ }^{12,13}$ (Chart 1). Replacement of two $\mathrm{CH}$ groups in the fluorenone core by nitrogen atoms leads to a reduced dipole moment as compared to the parent fluorenone and thus should directly affect the self-assembly and luminescence. In order to probe this we aimed to study 4,5-diazafluoren-9-one (DAF) that has been described first in 1973 by Eckhard and Summers as an oxidation product of 1,10-phenanthroline. ${ }^{14}$ Since then it has been recognized as a valuable donor ligand for various transition metal complexes, which are particularly useful catalysts in allylic C-H oxidations, ${ }^{15}$ dehydrogenation of aldehydes and ketones, ${ }^{16,17}$ aerobic dehydrogenative Heck reactions, ${ }^{18,19} \alpha$-vinylidenation of aldehydes, ${ }^{20}$ aerobic $\mathrm{C}-\mathrm{H}$ aminations ${ }^{21}$ and oxidative cleavage of aldehydes to ynones. ${ }^{22}$ Furthermore, diazafluorenone derivatives and their corresponding metal complexes have also raised the interest of materials scientists due to their photoluminescence, ${ }^{23,24}$ use in dye sensitized solar cells ${ }^{25,26}$ and organic semiconductors. ${ }^{27}$ However, surprisingly little is known about liquid crystalline properties of diazafluorenones in contrast to the corresponding calamitic and bent-core type fluorenones ${ }^{4-7,12,13,28-41}$ and lyotropic fluorenones. ${ }^{8}$ Side chain modified fluorenones have also been used in crystal engineering to fabricate $2 \mathrm{D}$ assemblies. ${ }^{42,43}$ Lemieux studied azafluorenones which formed 
smectic C mesophases regarding their ferroelectricity. ${ }^{10}$ Tai reported diazafluorenone Schiff base amphiphiles. ${ }^{44}$ In order to broaden the scope of the diazafluorenone mesogen, we wondered whether attachment of linear or wedge-shaped mesogenic units to the diazafluorenone core should provide rigid compounds (Chart 1), which might help to correlate structural data of the crystalline solid state with those of mesophase type and stability as well as luminescence porperties.
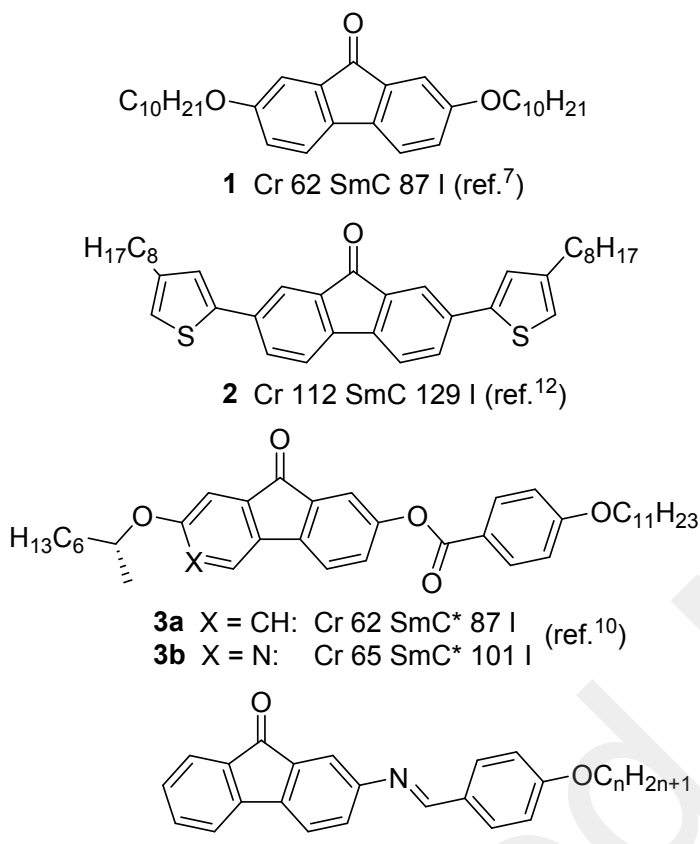

4a $n=12: \operatorname{Cr} 90 \mathrm{SmC} 100 \mathrm{SmA} 103 \mathrm{I}\left(\right.$ ref. $^{5}$ )
4b $\mathrm{n}=13: \operatorname{Cr} 92 \mathrm{SmA} 111 \mathrm{~N} 134 \mathrm{I}$

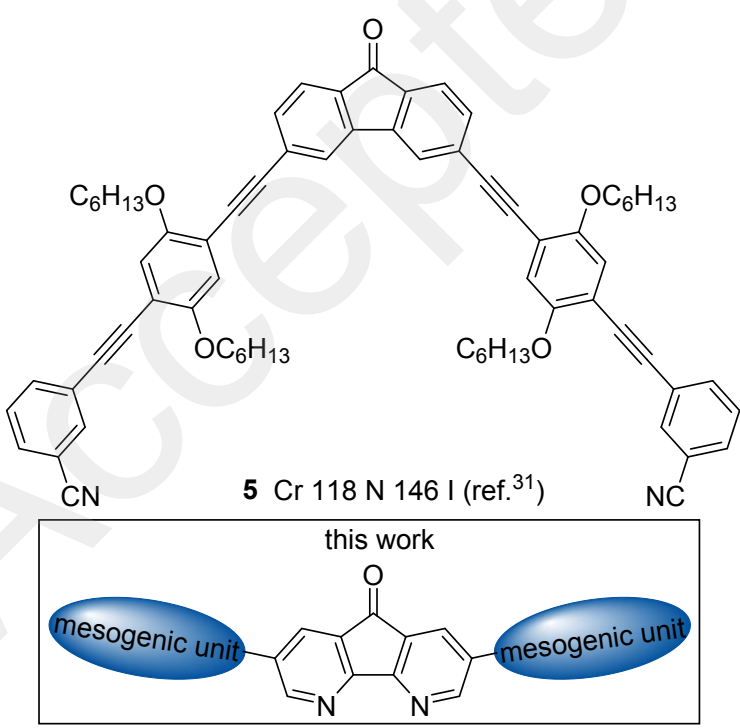

Chart 1. Some selected known fluorenone core liquid crystals 1-5 and our envisioned system. 


\section{RESULTS AND DISCUSSION}

Synthesis. The homologous series of symmetrical diazafluorenones $\mathbf{D A F}(\mathbf{O C n})_{\mathrm{m}}$ and an unsymmetrical derivative $(\mathbf{C 1 4 0})_{3} \mathbf{D A F}(\mathbf{O C 1 4})$ were synthesized as shown in Scheme 1.

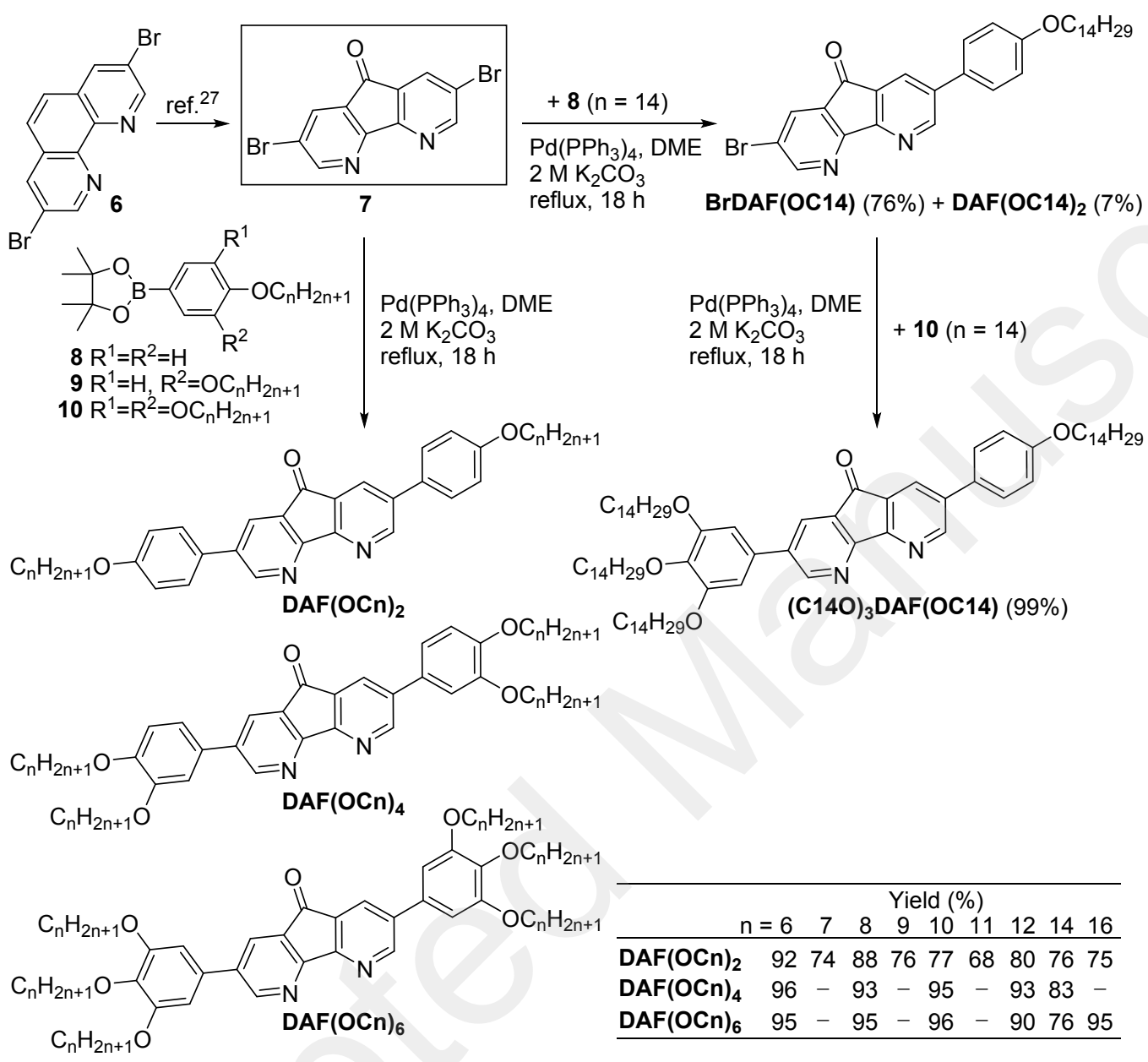

Scheme 1 Synthesis of target symmetrical diazafluorenones DAF(OCn $)_{\mathbf{m}}$ and unsymmetrical derivative (C14O) ${ }_{3} \mathbf{D A F}(\mathbf{O C 1 4})$ (for details see Supporting Information).

Known 3,8-dibromophenanthroline $6^{45-47}$ was converted to key intermediate 2,7-dibromo-4,5diazafluorenone 7 following a method by Huang. ${ }^{27}$ Suzuki cross coupling of 7 with the respective pinacol borolanes $\mathbf{8}^{-\mathbf{1 0}^{48-55}}$ gave 2,7-diphenyl-4,5-diazafluorenones $\mathbf{D A F}(\mathbf{O C n})_{2}$, $\operatorname{DAF}(\mathbf{O C n})_{4}$ and $\mathbf{D A F}(\mathbf{O C n})_{6}$ with 2,4 and 6 peripheral alkoxy chains, respectively. Treatment of 7 with 1 equiv. of pinacol borolane $8(n=14)$ provided the desired mono-coupling product BrDAF(OC14) in 76\% together with $\mathbf{D A F}(\mathbf{O C 1 4})_{2}(7 \%)$, which could be separated by column chromatography. Subsequent cross coupling of BrDAF(OC14) with borolane $10(n=$ 
14) yielded unsymmetrical (C14O) ${ }_{3} \mathbf{D A F}(\mathbf{O C 1 4})$ almost quantitatively. It should be emphasized that this sequential method is more reliable on a preparative scale than the one pot process, which provided a difficult to separate mixture of symmetrical DAF(OC14 $)_{2}$, DAF(OC14) 6 and unsymmetrical (C14O) ${ }_{3}$ DAF(OC14).

\section{X-ray crystal structure analysis. Compounds DAF(OC6 $)_{2}, \mathrm{DAF}(\mathrm{OC8})_{2}, \mathrm{DAF}(\mathrm{OC9})_{2}$} and $\mathbf{D A F}(\mathbf{O C 1 2})_{2}$ with two $\mathrm{C}_{6}, \mathrm{C}_{8}, \mathrm{C}_{9}$ and $\mathrm{C}_{12}$ side chains, respectively, gave single crystals, which were studied by X-ray crystal structure analysis (Figures 1-4, Table 1).

\section{Table 1. Crystal Data and Structural Refinement Details for Selected DAF(OCn $)_{2}{ }^{a}$}

\begin{tabular}{|c|c|c|c|c|}
\hline & $\mathrm{DAF}(\mathrm{OC6})_{2}$ & $\mathrm{DAF}(\mathrm{OC} 8)_{2}$ & $\mathrm{DAF}(\mathrm{OC} 9)_{2}$ & $\mathrm{DAF}(\mathrm{OC} 12)_{2}$ \\
\hline formula & $\mathrm{C}_{35} \mathrm{H}_{38} \mathrm{~N}_{2} \mathrm{O}_{3}$ & $\mathrm{C}_{39} \mathrm{H}_{46} \mathrm{~N}_{2} \mathrm{O}_{3}$ & $\mathrm{C}_{41} \mathrm{H}_{50} \mathrm{~N}_{2} \mathrm{O}_{3}$ & $\mathrm{C}_{47} \mathrm{H}_{62} \mathrm{~N}_{2} \mathrm{O}_{3}$ \\
\hline formula weight & 534.67 & 590.78 & 618.83 & 702.99 \\
\hline temperature $(\mathrm{K})$ & $130(2)$ & $130(2)$ & $100(2)$ & $110(2)$ \\
\hline$\lambda(\AA)$ & 1.54178 & 1.54178 & 0.71073 & 1.54178 \\
\hline crystal system & triclinic & triclinic & monoclinic & triclinic \\
\hline space group & $P \overline{1}$ & $P \overline{1}$ & $P 2{ }_{1} / \mathrm{n}$ & $P \overline{1}$ \\
\hline$a(\AA)$ & $4.8987(2)$ & $5.06340(10)$ & $11.7393(7)$ & $5.4135(5)$ \\
\hline$b(\AA)$ & $13.5905(6)$ & $22.4039(6)$ & $5.3920(4)$ & $11.2702(10)$ \\
\hline$c(\AA)$ & $22.2404(9)$ & $29.0032(8)$ & $52.865(3)$ & $32.507(3)$ \\
\hline$\alpha(\mathrm{deg})$ & $72.777(4)$ & $98.9720(10)$ & 90 & $99.509(7)$ \\
\hline$\beta(\mathrm{deg})$ & $88.586(4)$ & $91.776(2)$ & $95.425(4)$ & $92.311(7)$ \\
\hline$\gamma(\operatorname{deg})$ & $83.448(3)$ & $96.471(2)$ & 90 & $91.176(7)$ \\
\hline$V\left(\AA^{3}\right)$ & $1404.98(10)$ & $3225.20(14)$ & $3331.2(4)$ & 1953(3) \\
\hline$Z$ & 2 & 4 & 4 & 2 \\
\hline$D_{\mathrm{c}}\left(\mathrm{g} / \mathrm{cm}^{3}\right)$ & 1.264 & 1.217 & 1.234 & 1.195 \\
\hline$\mu\left(\mathrm{mm}^{-1}\right)$ & 0.631 & 0.595 & 0.077 & 0.565 \\
\hline GOF on $F^{2}$ & 1.003 & 1.017 & 1.090 & 1.040 \\
\hline $\mathrm{R}_{1}, w \mathrm{R}_{2}(\mathrm{I}>2 \alpha(\mathrm{I}))$ & $0.0526,0.1112$ & $0.0685,0.1651$ & $0.1295,0.3229$ & $0.0675,0.1422$ \\
\hline $\mathrm{R}_{1}, w \mathrm{R}_{2}$ (all data) & $0.0904,0.1224$ & $0.0984,0.1781$ & $0.1411,0.3268$ & $0.1309,0.1584$ \\
\hline $\begin{array}{l}\text { largest diff. peak and hole } \\
\left(\mathrm{e} / \AA^{3}\right)\end{array}$ & $0.214,-0.207$ & $0.254,-0.295$ & $0.488,-0.468$ & $0.231,-0.226$ \\
\hline
\end{tabular}

Compounds DAF(OC6) $)_{2}$ with the shortest chain length crystallized in the centrosymmetric space group $P \overline{1}$ with one molecule in the asymmetric unit. Both phenyl moieties are rotated 
out of plane with respect to the diazafluorenone core characterized by the torsion angles $\mathrm{C} 11-$ C10-C24-C25 and C8-C7-C12-C13 with $-24.4(4)^{\circ}$ and $-15.9(4)^{\circ}$, respectively.

(a)
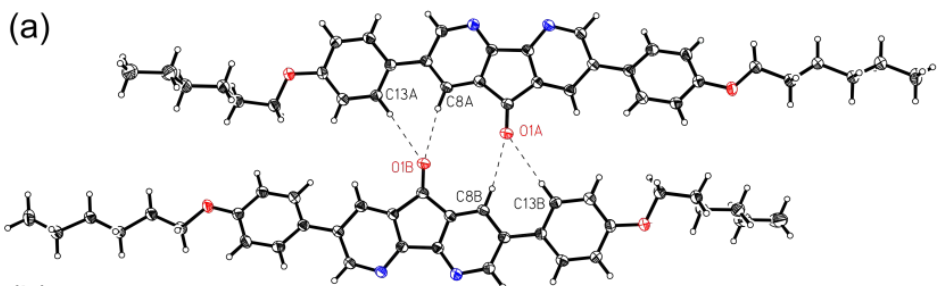

(b)

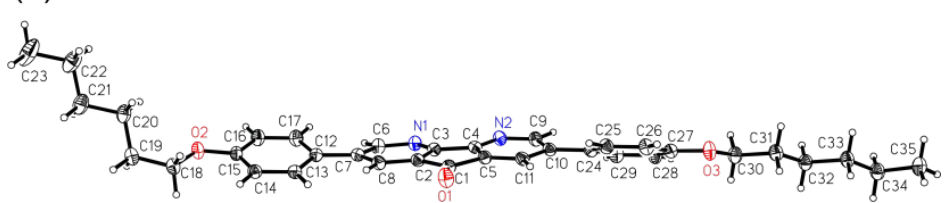

(c)

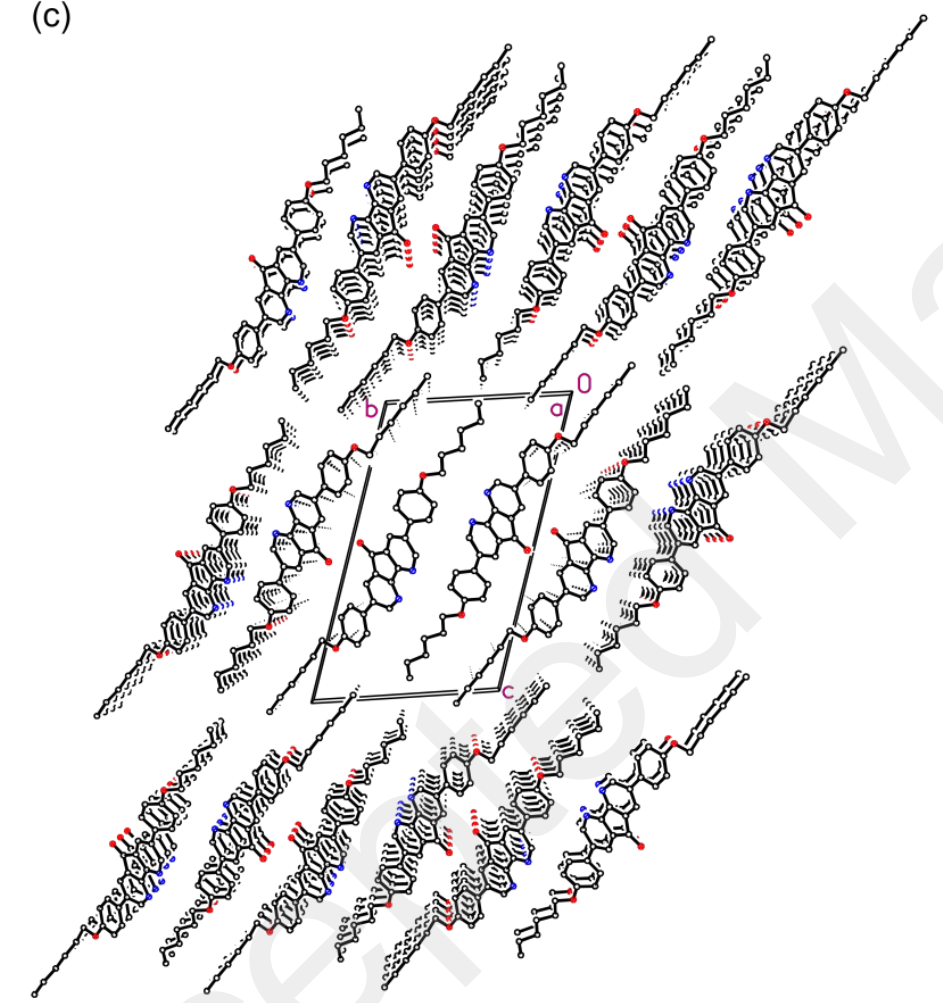

Figure 1. ORTEP drawing of the structure of DAF(OC6) $)_{2}$ in the solid state, top view (a) and side view (b) and the packing diagram viewed along the $b$ axis (c). The translation vector of the columns is along the $a$ axis and the layer-type orientation of the molecules is building up along the $c$ axis.

Only one of the alkoxy chains shows an all-trans zig-zag conformation with a nearly coplanar orientation of $8.5(2)^{\circ}$ to the attached phenyl moiety. The other alkoxy chain is strongly out of plane in relation to the attached phenyl moiety indicated by an interplanar angle of $64.4(4)^{\circ}$ (Figure $1 \mathrm{~b}$ ). There is a $\pi(\mathrm{C}-\mathrm{H}) \cdots \mathrm{O}$ interaction evident, which works 
pairwise vice versa between molecules generated by the inversion center (Figure 1a). The intermolecular stabilization is forced by the distances between the donor $\mathrm{H}$ atoms and the carbonyl oxygens of $2.33 \AA$ and $2.54 \AA$. The corresponding angles $\mathrm{C}-\mathrm{H} \cdots \mathrm{O}$ are $169^{\circ}$ and $163^{\circ}$. The packing diagram of the cellplot (Figure 1c) shows a stacking orientation of the molecules along the $b$ axis. The translation vector of the columns is along the $a$ axis and the layer-type orientation of the molecules is building up along the $c$ axis. Tilted layers are formed with a tilt angle of about $38.5^{\circ}$ with respect to the $c$ axis.

The higher homologue $\mathbf{D A F}(\mathbf{O C 8})_{2}$ crystallized in the centrosymmetric space group $P \overline{1}$ with two independent molecules in the asymmetric unit (Figure 2a).

(a)
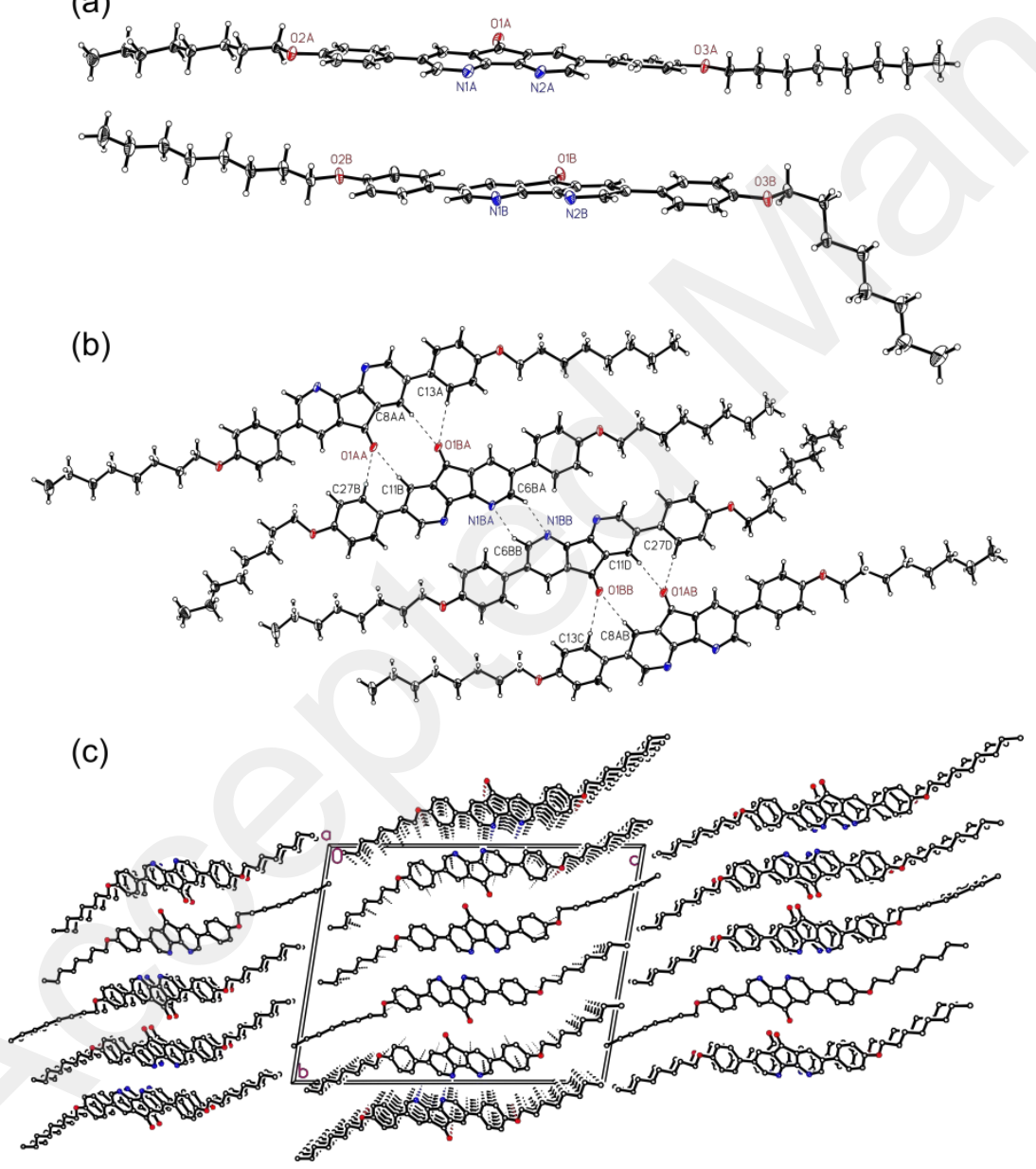

Figure 2. ORTEP drawing of the structure of $\mathbf{D A F}(\mathbf{O C 8})_{2}$ in the solid state, side view (a) and top view (b) and the packing diagram viewed along the $a$ axis (c). The translation direction of the layers is along the $c$ axis and the intermolecular hydrogen bond stabilization works along the $b$ axis. 
The alkoxy chains of one molecule are oriented in an all-trans zig-zag conformation similar to

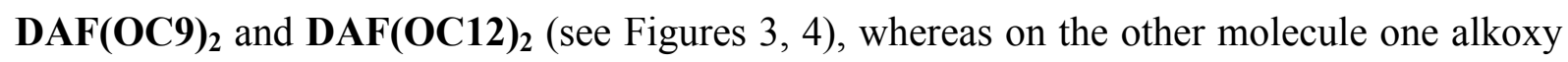
chain has an all-trans zig-zag orientation and one alkoxy chain is strongly out of plane oriented with respect to the attached phenyl moiety similar to $\mathbf{D A F}(\mathbf{O C 6})_{2}$ (see Figure 1). The observed packing of the alkoxy chains in $\mathbf{D A F}(\mathbf{O C 8})_{2}$ seems to resemble a mixture of DAF(OC6) ${ }_{2}$ and the higher homologues $\mathbf{D A F}(\mathbf{O C 9})_{2}$ and DAF(OC12 $)_{2}$. Both conformers of $\mathbf{D A F}(\mathbf{O C 8})_{2}$ are stabilized pairwise by weak $\pi(\mathrm{C}-\mathrm{H}) \cdots \mathrm{O}$ intermolecular hydrogen bond interactions. O1A works as acceptor and C27B-H27B together with C11B-H11B as bifurcated donor (Figure 2b). In the same way O1B interacts with $\mathrm{C} 8 \mathrm{~A}-\mathrm{H} 8 \mathrm{~A}$ and $\mathrm{C} 13 \mathrm{~A}-$ H13A. The $\mathrm{C}-\mathrm{H} \cdots \mathrm{O}$ distances range between $2.32 \AA$ to $2.60 \AA$ and the intervall of the associated angles is $133-172^{\circ}$. Those pairs are additionally stabilized by another neighbor pair which is generated by an inversion shift. This $\pi(\mathrm{C}-\mathrm{H}) \cdots \mathrm{N}$ hydrogen bond interaction acts vice versa with a $\mathrm{C}-\mathrm{H} \cdots \mathrm{H}$ distance of $2.39 \AA$ and a related angle of $152^{\circ}$ (Figure $2 \mathrm{~b}$ ). The packing diagram reveals a layer-type organization of the molecules with the stacking vector of the molecules along the $a$ axis and the translation direction of the layers along the $c$ axis (Figure 2c).

Compounds DAF(OC9) ${ }_{2}$ crystallized with one molecule in the asymmetric unit of the centrosymmetric space group $P 2_{1} / \mathrm{n}$. The alkoxy chains are oriented in an all-trans zig-zag conformation resulting in a perfect calamitic structure in the solid state (Figure $3 \mathrm{a}, \mathrm{b}$ ). The packing diagram (Figure 3c) shows a stacking behavior of the molecules along the $b$ axis. The translation direction of the stacking columns is along the $a$ axis and the layer-type orientation of the molecules along the $c$ axis. Tilted layers are formed with a tilt angle of about $45^{\circ}$ with respect to the $c$ axis. 
(a)
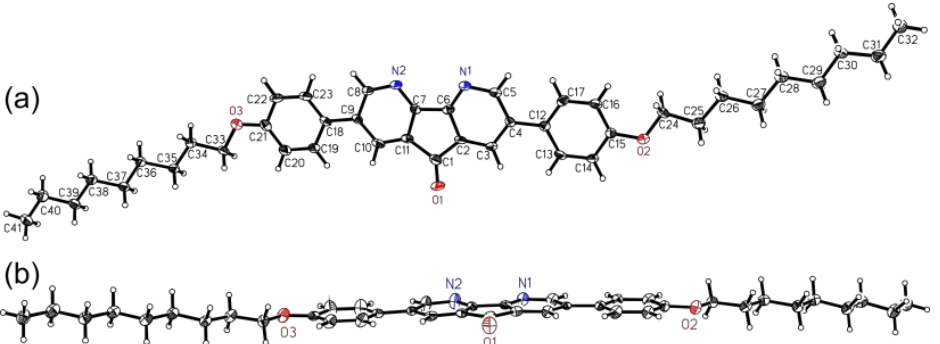

(c)

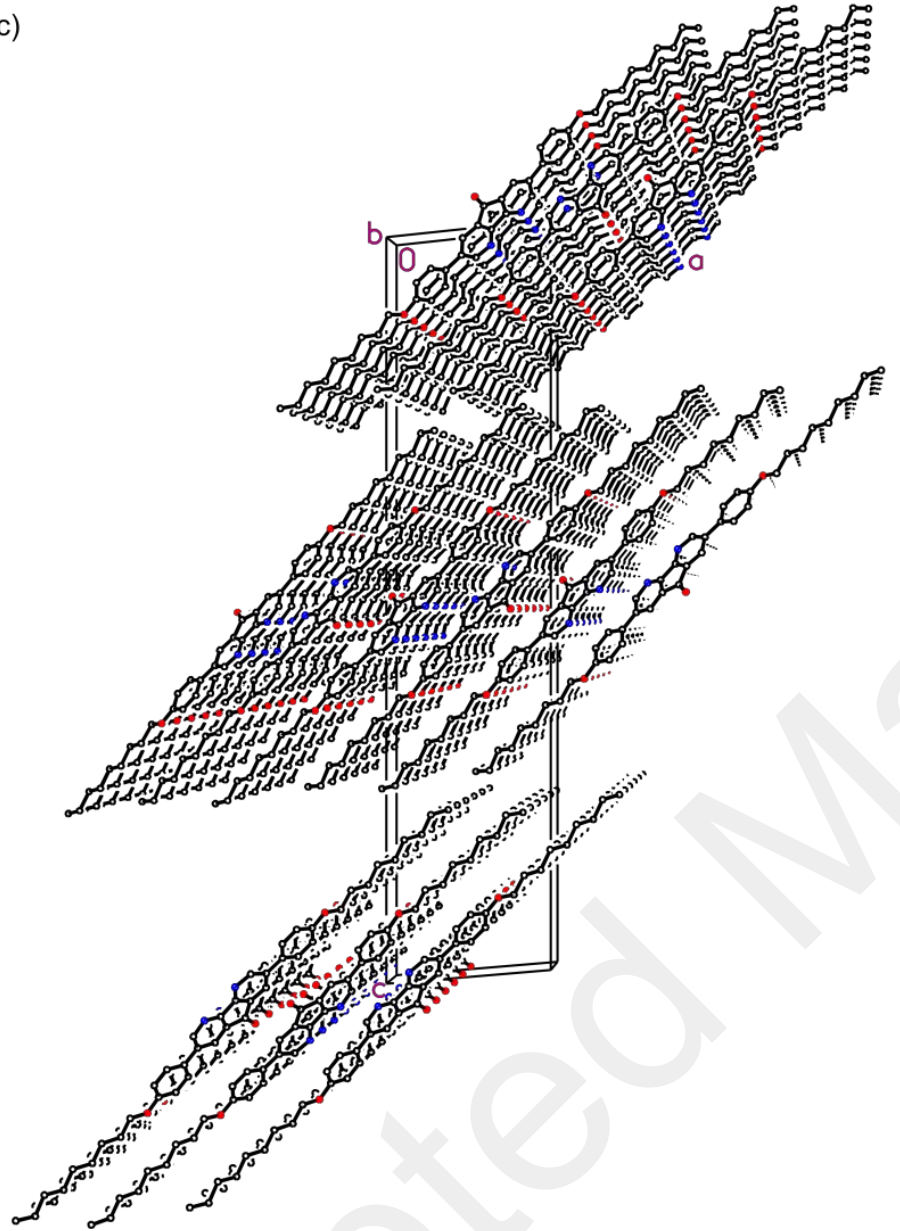

Figure 3. ORTEP drawing of the structure of DAF $(\mathbf{O C 9})_{2}$ in the solid state, top view (a) and side view (b) and the packing diagram viewed along the $b$ axis (c). It must be noted that the R1 value converged at rather weak $13 \%$ due to insufficient crystal quality. Nevertheless the overall standard deviation of the $\mathrm{C}-\mathrm{C}$ distances is approximately $0.8 \mathrm{pm}$.

DAF(OC12) ${ }_{2}$ crystallized in the centrosymmetric space group $P \overline{1}$ with one molecule in the asymmetric unit. The all-trans zig-zag conformation (Figure S18) of the alkoxy chains is comparable to that in $\mathbf{D A F}(\mathbf{O C} 9)_{2}$ leading again to a layer type organization. The packing plot reveals a face to face stacking of the molecules along the $a c$ diagonal. The translation of the stacking columns is along the $b$ axis generated by the inversion center (Figure 4). 


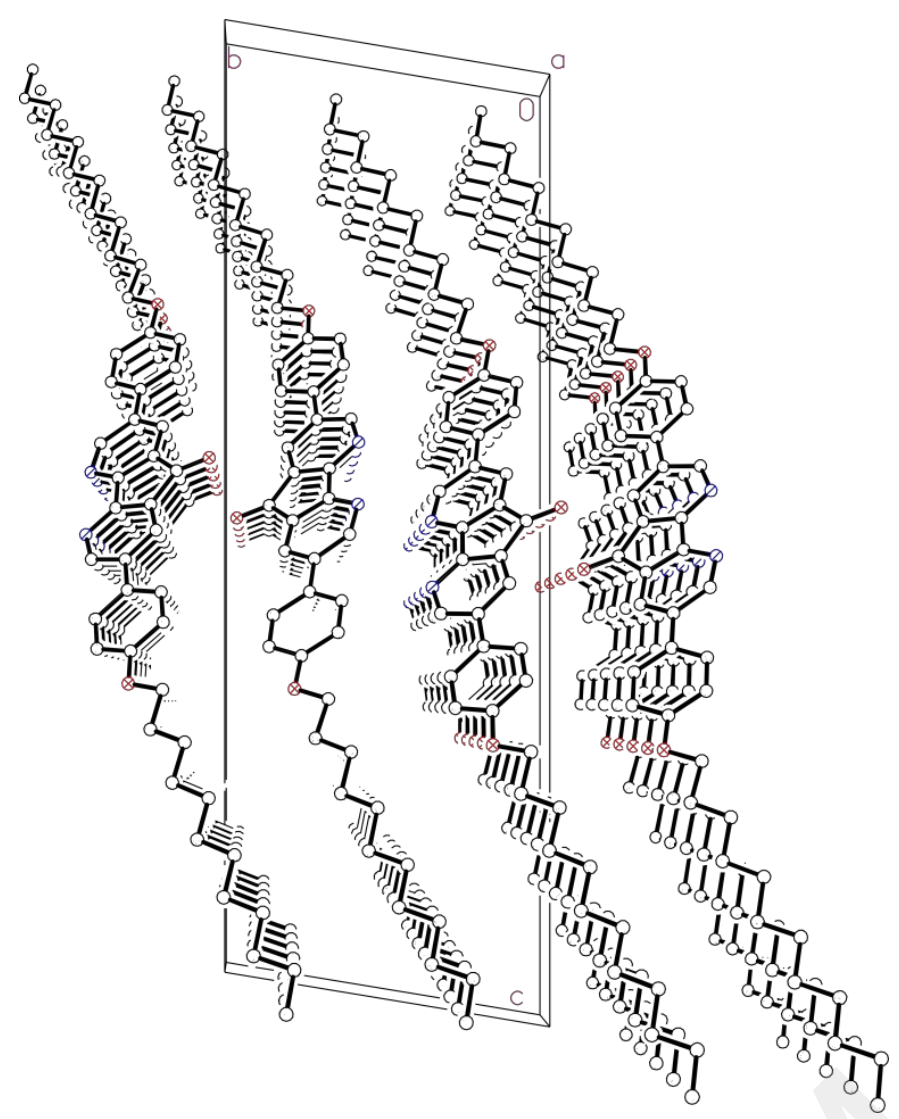

Figure 4. Packing diagram of $\mathbf{D A F}(\mathbf{O C 1 2})_{2}$ viewed along the $a$ axis. The completeness of data reached ca. $90 \%$, which may be caused by the $\mathrm{Cu}$ source and depends on the orientation of the crystal in context of the geometric limitation of the device at large theta angles. However, this is not relevant for the discussion.

The packing diagrams of both $\mathbf{D A F}(\mathbf{O C 9})_{2}$ and $\mathbf{D A F}(\mathbf{O C 1 2})_{2}$ (Figures 3c, 4) reveal a layer type orientation suggesting a prevalence for lamellar self-assembly in the mesophase as well.

Studies on mesomorphism. Mesomorphic properties of diazafluorenones $\mathbf{D A F}(\mathbf{O C n})_{\mathrm{m}}$ were investigated by differential scanning calorimetry (DSC), polarizing optical microscopy (POM) and X-ray diffraction (WAXS, SAXS). The DSC results are summarized in Table 2.

All members of the series $\mathbf{D A F}(\mathbf{O C n})_{2}$ with two peripheral alkoxy chains showed enantiotropic mesomorphism (Table 2). In contrast to derivatives with short chain lengths $\left(\mathrm{C}_{6}-\mathrm{C}_{8}\right)$, whose DSC curves displayed two endothermal phase transitions besides the clearing transition upon heating (Figure 5a), the second phase disappeared for $\mathbf{D A F}(\mathbf{O C 9})_{2}$ as well as 
higher homologues $\mathbf{D A F}(\mathbf{O C n})_{2} \quad(\mathrm{n}=10,11,12,14,16)$. Their $\mathrm{DSC}$ curves revealed endothermal melting and clearing transitions, as exemplified for $\mathbf{D A F}(\mathbf{O C 1 2})_{2}$ (Figure 5b).

Table 2. Phase Transition Temperature $\left({ }^{\circ} \mathrm{C}\right)$ and Enthalpies $\Delta H\left(\mathrm{~kJ} \mathrm{~mol}^{-1}\right)$ of DAF(OCn) $)_{\mathrm{m}}$ and $(\mathrm{C14O}) \mathrm{DAF}(\mathrm{OC14})_{3}$ upon Second Heating (rate $\left.5 \mathrm{~K} \mathrm{~min}^{-1}\right)^{a}$

\begin{tabular}{|c|c|c|c|c|c|}
\hline compound & phase & $T_{\mathrm{m}}(\Delta H)$ & phase & $T_{\mathrm{c}}(\Delta H)$ & phase \\
\hline \multirow{2}{*}{$\mathrm{DAF}(\mathrm{OC6})_{2}$} & $\mathrm{Cr}$ & $222(24.1)$ & $\mathrm{SmC}$ & $256(2.7)$ & \\
\hline & & & $\mathrm{N}$ & $302(1.3)$ & I \\
\hline \multirow[t]{2}{*}{$\mathrm{DAF}(\mathrm{OC} 7)_{2}$} & $\mathrm{Cr}$ & $214(26.0)$ & $\mathrm{SmC}$ & $262(4.3)$ & \\
\hline & & & $\mathrm{N}$ & $287(1.6)$ & I \\
\hline \multirow{2}{*}{$\mathrm{DAF}(\mathrm{OC} 8)_{2}$} & $\mathrm{Cr}$ & $210(29.1)$ & $\mathrm{SmC}$ & $272(5.5)$ & \\
\hline & & & $\mathrm{N}$ & $283(2.1)$ & I \\
\hline $\mathrm{DAF}(\mathrm{OC} 9)_{2}$ & $\mathrm{Cr}$ & $198(26.2)$ & $\mathrm{SmC}$ & $266(9.4)$ & $\mathrm{I}$ \\
\hline $\mathrm{DAF}(\mathrm{OC10})_{2}$ & $\mathrm{Cr}$ & $193(25.6)$ & $\mathrm{SmC}$ & $266(11.5)$ & I \\
\hline $\mathrm{DAF}(\mathrm{OC} 11)_{2}$ & $\mathrm{Cr}$ & $191(27.6)$ & $\mathrm{SmC}$ & $264(10.6)$ & I \\
\hline $\mathrm{DAF}(\mathrm{OC12})_{2}$ & $\mathrm{Cr}$ & $189(31.4)$ & $\mathrm{SmC}$ & $261(13.7)$ & I \\
\hline $\mathrm{DAF}(\mathrm{OC14})_{2}$ & $\mathrm{Cr}^{b}$ & $178(21.1)$ & $\mathrm{SmC}$ & $239(9.7)$ & I \\
\hline $\mathrm{DAF}(\mathrm{OC} 16)_{2}$ & $\mathrm{Cr}^{c}$ & $175(20.0)$ & $\mathrm{SmC}$ & $230(10.6)$ & I \\
\hline $\mathrm{DAF}(\mathrm{OC6})_{4}$ & $\mathrm{Cr}^{d}$ & - & - & $130(46.3)$ & I \\
\hline $\mathrm{DAF}(\mathrm{OC} 8)_{4}$ & $\mathrm{Cr}^{d}$ & - & - & $123(44.1)$ & I \\
\hline $\mathrm{DAF}(\mathrm{OC10})_{4}$ & $\mathrm{Cr}^{d}$ & - & - & $127(64.6)$ & I \\
\hline $\mathrm{DAF}(\mathrm{OC12})_{4}$ & $\mathrm{Cr}^{d}$ & - & - & $126(82.7)$ & I \\
\hline $\mathrm{DAF}(\mathrm{OC14})_{4}$ & $\mathrm{Cr}^{d}$ & - & - & $125(99.3)$ & I \\
\hline $\mathrm{DAF}(\mathrm{OC} 6)_{6}$ & $\mathrm{Cr}^{d}$ & - & - & $94(20.8)$ & I \\
\hline $\mathrm{DAF}(\mathrm{OC8})_{6}$ & $\mathrm{Cr}^{d}$ & $87(17.5)$ & $\mathrm{Col}_{\mathrm{h}}$ & $95(4.0)$ & I \\
\hline $\mathrm{DAF}(\mathrm{OC10})_{6}$ & $\mathrm{Cr}^{d}$ & $84(17.2)$ & $\mathrm{Col}_{\mathrm{h}}$ & $96(5.0)$ & I \\
\hline $\mathrm{DAF}(\mathrm{OC12})_{6}$ & $\mathrm{Cr}$ & 85 (19.4) & $\mathrm{Col}_{\mathrm{h}}$ & $93(5.8)$ & I \\
\hline \multirow[t]{3}{*}{$\mathrm{DAF}(\mathrm{OC14})_{6}$} & $\mathrm{Cr}$ & $6(42.6)$ & $\mathrm{Col}_{\mathrm{ro}}$ & $36(1.3)$ & \\
\hline & & & $\mathrm{Col}_{\mathrm{rd}}$ & $79(16.6)$ & \\
\hline & & & $\mathrm{Col}_{\mathrm{h}}$ & $88(6.9)$ & $\mathrm{I}$ \\
\hline \multirow[t]{3}{*}{$\mathrm{DAF}(\mathrm{OC16})_{6}$} & $\mathrm{Cr}$ & $30(49.6)$ & $\mathrm{Col}_{1}$ & $50(15.5)$ & \\
\hline & & & $\mathrm{Col}_{2}$ & $71(6.0)$ & \\
\hline & & & $\mathrm{Col}_{\mathrm{h}}$ & $82(5.9)$ & $\mathrm{I}$ \\
\hline$(\mathrm{C14O})_{3} \mathrm{DAF}(\mathrm{OC14})$ & $\mathrm{Cr}$ & 30 & $\mathrm{Col}_{\mathrm{h}}$ & 80 & I \\
\hline \multicolumn{6}{|c|}{$\begin{array}{l}{ }^{a} \text { Phases observed: crystalline }(\mathrm{Cr}) \text {, nematic }(\mathrm{N}) \text {, smectic } \mathrm{C}(\mathrm{SmC}) \text {, columnar } \\
\text { hexagonal }\left(\mathrm{Col}_{\mathrm{h}}\right) \text {, columnar rectangular ordered }\left(\mathrm{Col}_{\mathrm{r}}\right) \text {, disordered }\left(\mathrm{Col}_{\mathrm{rd}}\right) \text {, iso- } \\
\text { tropic liquid }(\mathrm{I}) \cdot{ }^{b} \text { Additional transition } \mathrm{Cr}_{1} 159(7.6) \mathrm{Cr}_{2} \cdot{ }^{c} \text { Additional transition } \\
\mathrm{Cr}_{1} 149(14.3) \mathrm{Cr}_{2} \cdot{ }^{d} \text { Heating rate } 10 \mathrm{~K} \mathrm{~min}^{-1} \text {. }\end{array}$} \\
\hline
\end{tabular}

Diazafluorenones DAF(OCn $)_{4}$ with four alkoxy chains in the periphery were devoid of any mesomorphism (Table 2). It should be noted that Lodeiro and coworkers ${ }^{56}$ recently reported for borondifluoride diketonato complexes that certain combinations of symmetrical 
and unsymmetrical mono-, bis- and trisalkoxyphenyl side chains were non-mesogenic due to insufficient space filling.
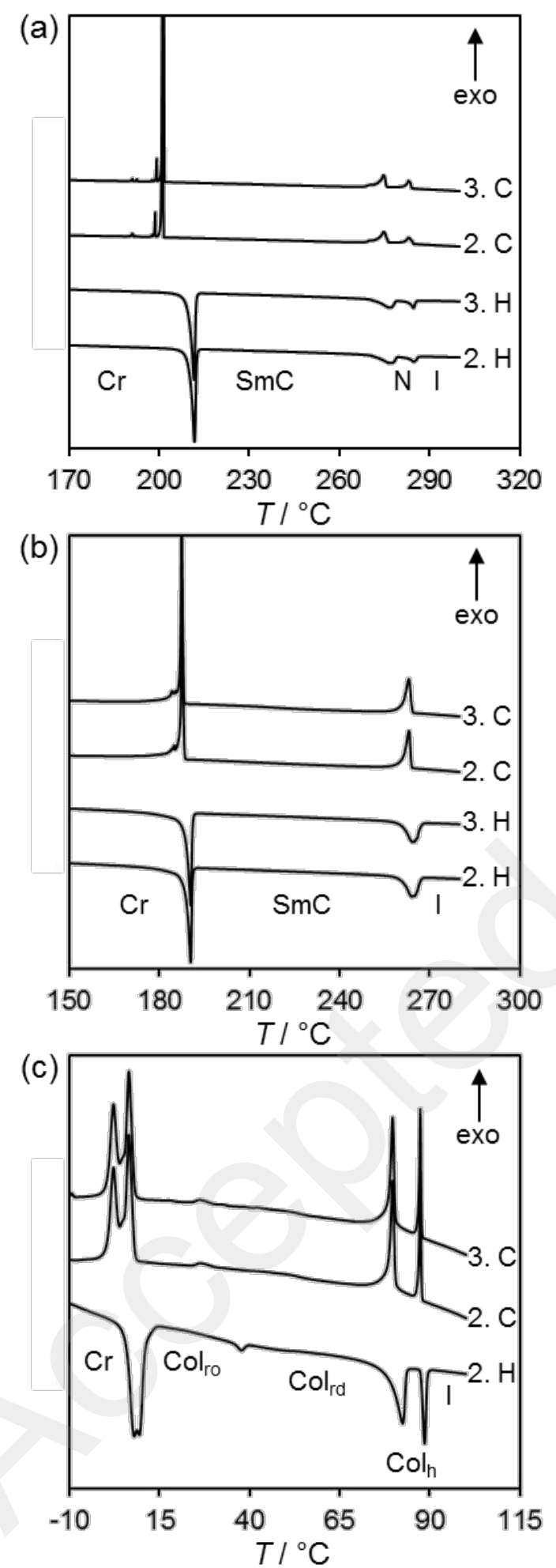

Figure 5. DSC curves of selected diazafluorenones: (a) DAF(OC8) ${ }_{2}$, (b) DAF(OC12) 2 and

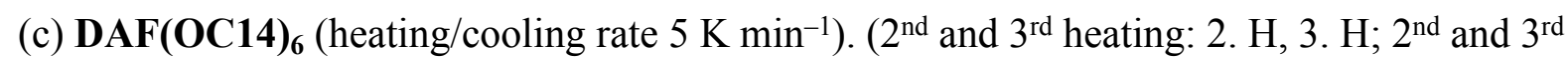
cooling: 2. C, 3. C). 
Sixfold alkoxy substituted diazafluorenones $\mathbf{D A F}(\mathbf{O C n})_{6}$ again formed enantiotropic mesophases, except the shortest chain member $\mathbf{D A F}(\mathbf{O C 6})_{\mathbf{6}}$ which was non-mesomorphic (Table 2). Whereas compounds $\mathbf{D A F}(\mathbf{O C n})_{6}(\mathrm{n}=8,10,12)$ displayed only one mesophase (Table 2), an additional phase transition was observed for DAF(OC14) 6 and DAF(OC16)6 with $\mathrm{C}_{14}$ and $\mathrm{C}_{16}$ chains. As shown for $\mathbf{D A F}(\mathbf{O C 1 4})_{6}$ in Figure 5c, in the DSC curve an endothermal crystalline to mesophase transition at $6^{\circ} \mathrm{C}$, followed by two endothermal mesophase-to-mesophase transitions at $36^{\circ} \mathrm{C}$ and at $79^{\circ} \mathrm{C}$ and subsequent clearing into the isotropic liquid at $88^{\circ} \mathrm{C}$ were visible upon second heating.

From the graphical presentation of the DSC results, the following trend could be observed for the series DAF(OCn) 2 (Figure 6a). Both melting and clearing points decreased with increasing chain lengths. The nematic phase widths decreased from $\mathrm{C}_{6}$ to $\mathrm{C}_{8}$, while the temperature ranges of the smectic $\mathrm{C}$ phase increased and then remained relatively constant for longer $\mathrm{C}_{9}-\mathrm{C}_{16}$ chains.
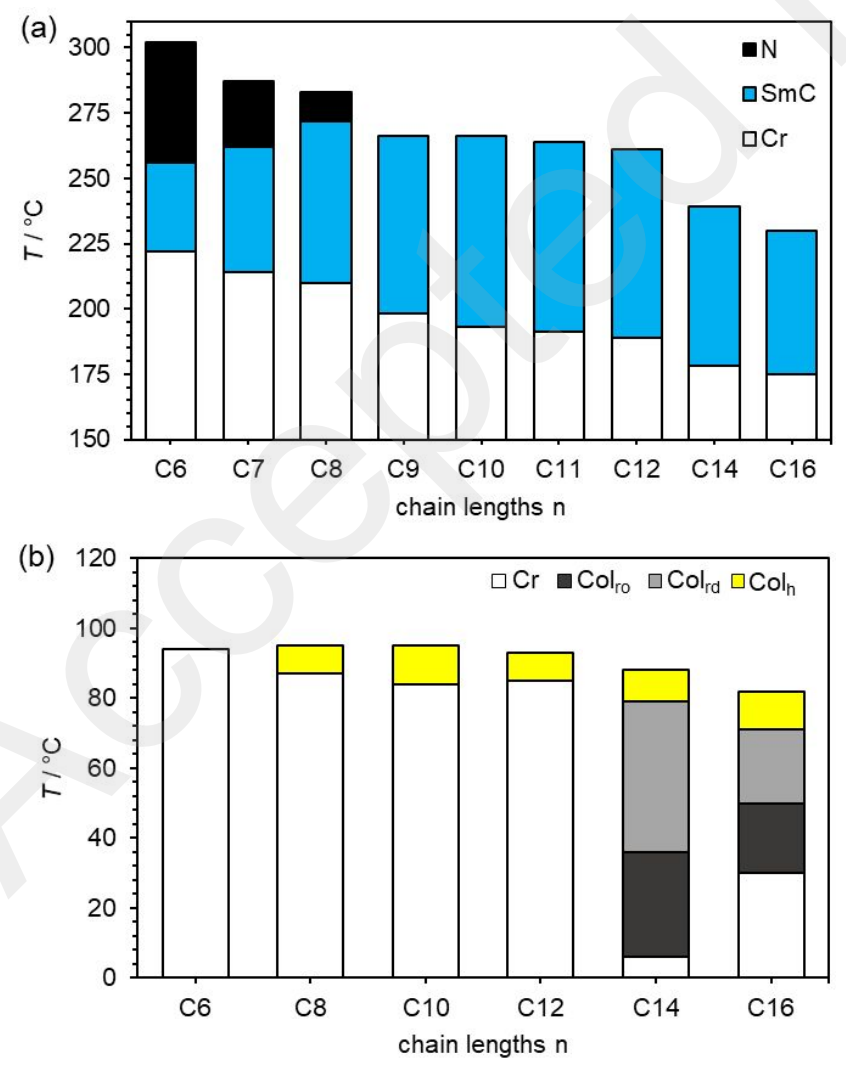

Figure 6. Temperature ranges of the mesophases of (a) DAF(OCn $)_{2}$ and (b) DAF(OCn $)_{6}$ with different chain lengths obtained by DSC upon second heating. 
Within the series DAF(OCn) ${ }_{6}$ a slight decrease of clearing points together with more or less constant melting points (up to $\mathrm{C}_{12}$ ) led to smaller columnar mesophase ranges (Figure 6b). The presence of two additional columnar mesophases at lower temperatures resulted in very broad phase widths of $82 \mathrm{~K}$ and $52 \mathrm{~K}$ for $\mathbf{D A F}(\mathbf{O C 1 4})_{6}$ and DAF(OC16), respectively.

Texture analysis by POM revealed the formation of broken fan-shaped and Schlieren textures for $\mathbf{D A F}(\mathbf{O C 9})_{2}$, $\mathbf{D A F}(\mathbf{O C 1 2})_{2}$ and their homologues $\mathbf{D A F}(\mathbf{O C n})_{2}$, indicating a smectic C mesophase (Figure S2). The texture of $\mathbf{D A F}(\mathbf{O C} 9)_{2}$ is depicted in Figure $7 \mathrm{a}$ as an example. The additionally observed droplets for the short chain diazafluorenones $\operatorname{DAF}(\mathbf{O C n})_{2}(\mathrm{n}=6-8)$ at high temperature upon cooling from the isotropic liquid are characteristic of a nematic phase (Figure $7 b$ ). Compounds $\mathbf{D A F}(\mathbf{O C n})_{6}(\mathrm{n} \geq 8)$ typically displayed fan-shaped textures with line defects and homeotropic alignment upon cooling from the isotropic liquid indicating a columnar $(\mathrm{Col})$ mesophase. In the case of DAF(OC14) 6 , the fan-shaped texture observed at $82^{\circ} \mathrm{C}$ (Figure 7c) changed its color upon further cooling to $78^{\circ} \mathrm{C}$ (Figure $7 \mathrm{~d}$ ), suggesting a transition from one columnar phase into a second one.
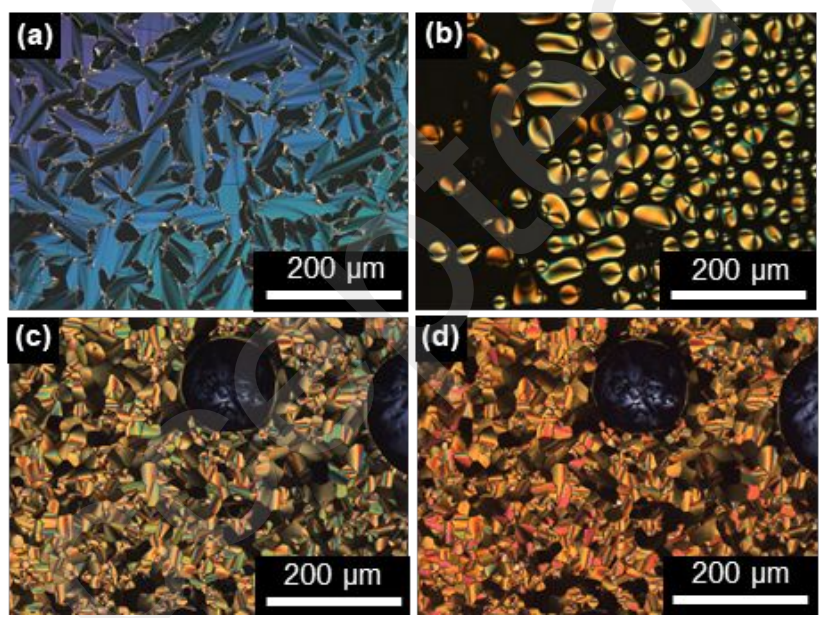

Figure 7. Textures of diazafluorenone derivatives as seen between crossed polarizers upon

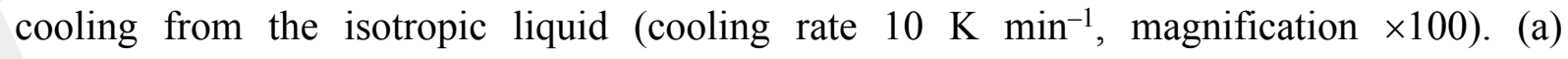
DAF(OC9) $)_{2}$ at $255^{\circ} \mathrm{C}$, (b) $\mathbf{D A F}(\mathbf{O C 6})_{2}$ at $300^{\circ} \mathrm{C}$, (c, d) $\mathbf{D A F}(\mathbf{O C 1 4})_{6}$ at $86^{\circ} \mathrm{C}$ and $78^{\circ} \mathrm{C}$, respectively, the color change of the textures indicated a transition from a columnar to another columnar mesophase (cooling rate $1 \mathrm{~K} \mathrm{~min}^{-1}$, magnification $\times 100$ ). 
X-ray diffraction (XRD) investigations. In order to verify the mesophase geometries, diazafluorenones DAF $(\mathbf{O C n})_{\mathbf{m}}$ were studied by XRD. X-ray scattering of calamitic DAF(OC9) ${ }_{2}$ exhibited a sharp reflection in the small-angle region which was assigned as (001) and a broad halo at $4.4 \AA$ in the wide-angle region typical for smectic phase geometries (Figure 8a). Further support for the assigned mesophase came from the temperature-dependent layer distances $d_{001}$ calculated from the (001) reflection. Their increase with rising temperature is common for smectic C phases (Figure $8 b$ ). ${ }^{57-61}$
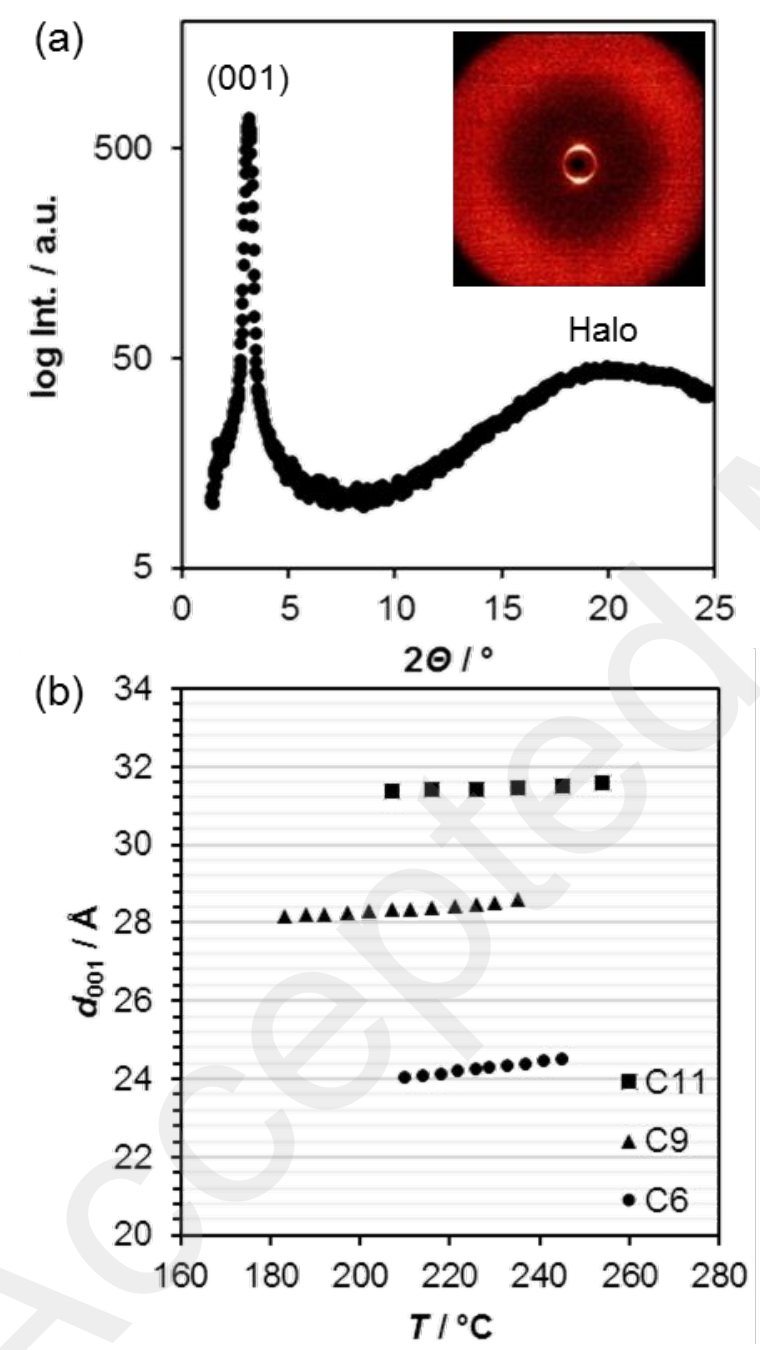

Figure 8. (a) Wide-angle scattering (WAXS) profile of the LC phase of $\mathbf{D A F}(\mathbf{O C 9})_{2}$ at $207^{\circ} \mathrm{C}$; inset: the corresponding diffraction pattern. (b) Layer spacing temperature dependency for DAF(OC6) 2 , DAF(OC9) 2 and DAF(OC11) 2 . 
The homologues $\mathbf{D A F}(\mathbf{O C 6})_{2}$ and $\mathbf{D A F}(\mathbf{O C 1 1})_{2}$ gave comparable results. The XRD data are listed in Table 3. Due to the high temperatures $\left(256-300^{\circ} \mathrm{C}\right)$, the nematic $(\mathrm{N})$ phases could not be examined by XRD measurements.

Table 3. X-Ray Diffraction Data of Diazafluorenones DAF(OCn)

\begin{tabular}{llll} 
Compound & Mesophase & $d$-value / $\AA$ & $\begin{array}{l}\text { Miller } \\
\text { indices }\end{array}$ \\
\hline DAF(OC6) & SmC & 24.2 & $(001)$ \\
& at $226^{\circ} \mathrm{C}$ & 4.4 & $($ Halo) \\
DAF(OC9) 2 & SmC & 28.4 & $(001)$ \\
& at $216^{\circ} \mathrm{C}$ & 4.3 & $($ Halo) \\
DAF(OC11) & SmC & 31.4 & $(001)$ \\
& at $207^{\circ} \mathrm{C}$ & 15.7 & $(002)$ \\
& & 4.8 & (Halo) \\
\hline
\end{tabular}

The results of XRD studies of $\mathbf{D A F}(\mathbf{O C n})_{6}$ are summarized in Table 4. The short chain derivatives DAF(OC8) 6 and DAF(OC10) 6 gave only the (10) reflection in SAXS experiments. However, due to the similarity of the POM textures with those of DAF(OC12 $)_{6}$ (Figure S3) a $\mathrm{Col}_{\mathrm{h}}$ phase was assigned as well. In the case of $\mathbf{D A F}(\mathbf{O C 1 2})_{6}$, an ordered diffractogram was obtained at $93^{\circ} \mathrm{C}$, which revealed a hexagon pattern within the (10) reflex with an azimuthal angle of $60^{\circ}$ supporting the $\mathrm{Col}_{\mathrm{h}}$ phase (Figure 9a). In the WAXS profile of DAF(OC12) 6 a diffuse halo was detected at $4.6 \AA$ (Figure 9b).

In the SAXS profile of $\mathbf{D A F}(\mathbf{O C 1 6})_{6}$ at $81^{\circ} \mathrm{C}$ three distinct reflections are visible in a ratio of $1: 1 / \sqrt{ } 3: 1 / 2$, which were indexed as (10), (11) and (20) typical for a hexagonal columnar mesophase with p6mm symmetry (Figure 9c). In the wide-angle region a broad halo caused by the molten alkoxy side chains was observed at $4.6 \AA$ (Figure 9d). 

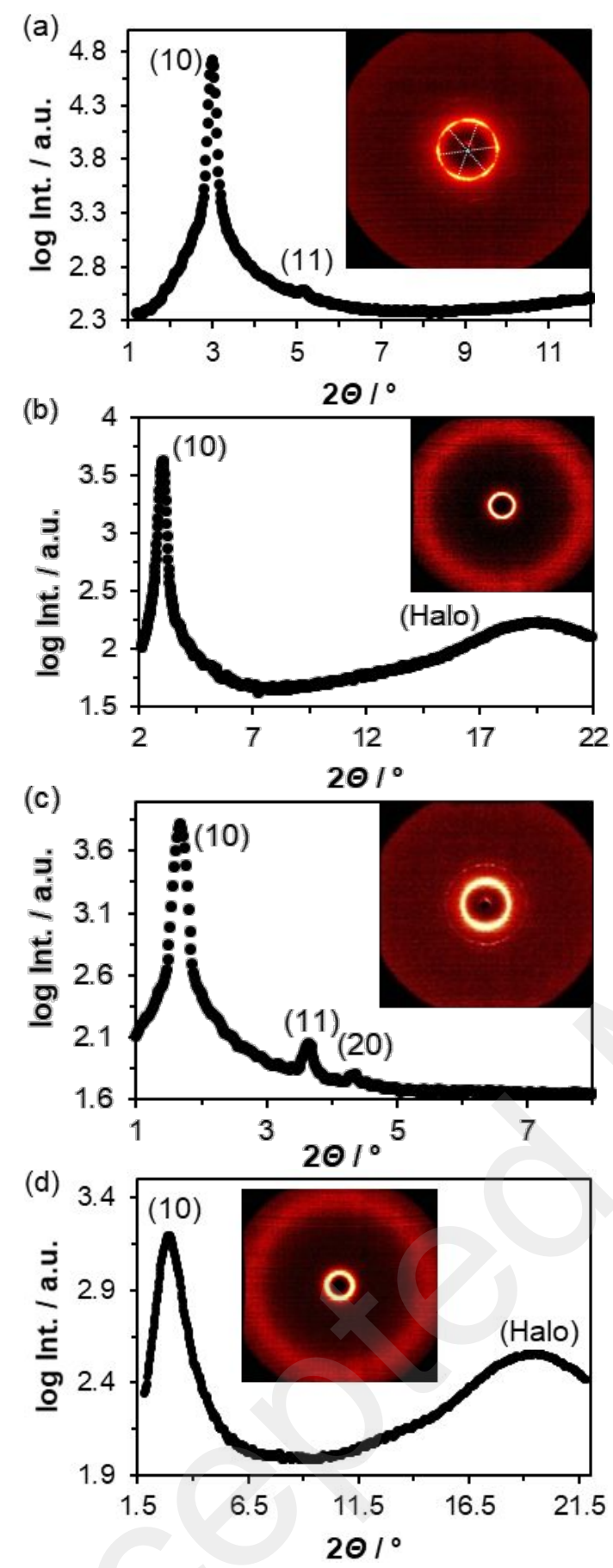

Figure 9. (a) SAXS profile of the LC phase of DAF(OC12) ${ }_{6}$ at $93^{\circ} \mathrm{C}$. (b) WAXS profile of the LC phase of DAF $(\mathbf{O C 1 2})_{6}$ at $90^{\circ} \mathrm{C}$. (c) SAXS profile of the mesophase of DAF $(\mathbf{O C 1 6})_{6}$ at $81{ }^{\circ} \mathrm{C}$. (d) WAXS profile of the mesophase of DAF $(\mathbf{O C 1 6})_{6}$ at $84^{\circ} \mathrm{C}$. Inset: the corresponding diffraction patterns.

In the case of $\mathbf{D A F}(\mathbf{O C 1 4})_{6}$, two additional mesophases were identified at lower temperatures. The SAXS profile revealed a set of eight reflections, indexed as (11), (12), (22), (40), (33), (14), (44) and (25) at $49^{\circ} \mathrm{C}$, which did not change upon further cooling to $16^{\circ} \mathrm{C}$ 
(Figure 10a). These reflections fulfil the symmetry requirements for a $p 2 g g$ space group ( $h+k=$ no conditions, $h 0=2 n, 0 k=2 n)$ and thus $\mathrm{Col}_{\mathrm{r}}$ phases with $p 2 g g$ symmetry were assigned. ${ }^{62}$
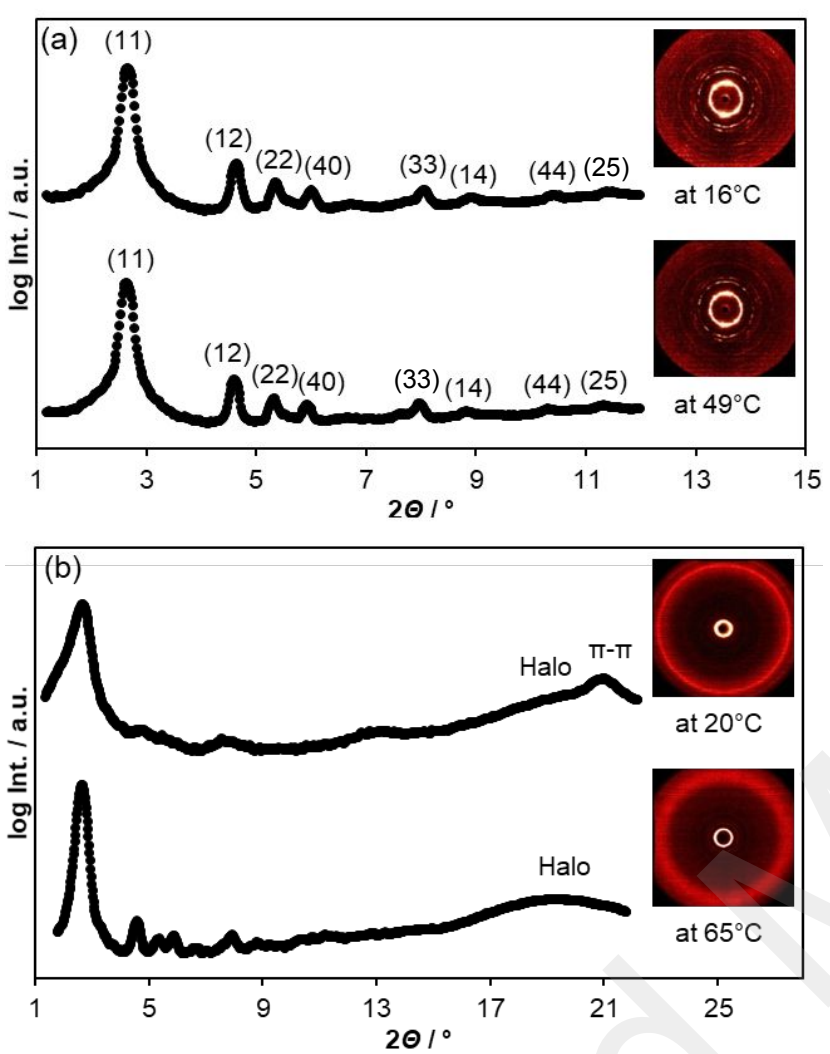

Figure 10. (a) SAXS profiles of $\mathrm{DAF}(\mathbf{O C 1 4})_{6}$ and diffraction pattern (inset) at $16^{\circ} \mathrm{C}$ and $49^{\circ} \mathrm{C}$, (b) WAXS profiles of DAF(OC14) ${ }_{6}$ and diffraction pattern (inset) at $20^{\circ} \mathrm{C}$ and $65^{\circ} \mathrm{C}$.

The wide-angle region showed a broad halo at $4.6 \AA$ at $65^{\circ} \mathrm{C}$ and upon further cooling to $20^{\circ} \mathrm{C}$ besides the halo $(4.3 \AA)$ an additional reflection at $4.2 \AA$ caused by the intracolumnar $\pi-\pi$ interactions (Figure 10b). Although this distance is larger than the expected value of $3.5 \AA$ for $\pi-\pi$ interactions with face-to-face stacking, ${ }^{63}$ it should be noted that the single crystal X-ray data revealed $\pi-\pi$ distances of 3.4-4.0 $\AA$ for diazafluorenone $\mathbf{D A F}(\mathbf{O C 6})_{2}$ with the shortest chains and 3.6-4.0 $\AA$ for homologue DAF(OC12)2. Furthermore, similar distances have been reported for other columnar liquid crystals. ${ }^{63-65}$ For example, Matsumoto rationalized experimental values of $4.1 \AA$ for $\mathrm{Col}_{\mathrm{ro}}$ phases by the edge-to-edge type stacking of the mesogens in the column. ${ }^{63}$ 
Therefore, the presence of an ordered rectangular columnar $\left(\mathrm{Col}_{\mathrm{ro}}\right)$ mesophase at ambient temperature, but a disordered rectangular columnar $\left(\mathrm{Col}_{\mathrm{rd}}\right)$ mesophase at higher temperatures seems to be reasonable. The observed phase sequence of one (or two) rectangular columnar phases at lower temperatures followed by a hexagonal columnar phase at higher temperatures is in good agreement with similar phase behavior of non-discoid ${ }^{66-70}$ and discoid mesogens ${ }^{71,72}$ and has been examined theoretically. ${ }^{73-75}$ However, the lattice parameters changed slightly during the $\operatorname{Col}_{\mathrm{ro}}-\mathrm{Col}_{\mathrm{rd}}$ transition $(\Delta a=0.7 \AA, \Delta b=0.2 \AA)$, although a small but distinct endothermal peak was visible in the DSC curve (Figure $5 \mathrm{c}, \Delta H=1.3 \mathrm{~kJ} \mathrm{~mol}^{-1}$ ). Wróbel reported similar lattice parameter changes $(\Delta a=0.9 \AA, \Delta b=0.3 \AA)$ for vanadyl salene complexes but could not observe the $\mathrm{Col}_{\mathrm{ro}}-\mathrm{Col}_{\mathrm{rd}}$ transition peak in the $\mathrm{DSC},{ }^{76}$ while rod-like diacetylenes published by Matsumoto revealed a small endothermal DSC peak $(\Delta H$ $\left.=0.03-0.14 \mathrm{~kJ} \mathrm{~mol}^{-1}\right)$ and larger changes of the $a$ - and $b$-values $(\Delta a=3.05 \AA, \Delta b=1.26 \AA) .{ }^{63}$ As no suitable XRD results (Figures S14 and S15) could be obtained for the two lower temperature mesophases of $\mathbf{D A F}(\mathbf{O C 1 6})_{6}, \mathrm{Col}_{\mathrm{ro}}$ and $\mathrm{Col}_{\mathrm{rd}}$ were assigned in analogy to

\section{DAF(OC14)}

Following the previously reported method 77,78 the number of molecules per unit cell $Z$ was calculated by the equation $Z=\frac{\rho \cdot N_{A} \cdot A \cdot h}{M}$ (density $\rho=1 \mathrm{~g} / \mathrm{cm}^{3}, N_{A}$ Avogadro factor, $A$ area of the unit cell calculated from the lattice parameters, $h$ height of the unit cell and $M$ molar mass of the mesogen $)^{77}$

giving $Z=4$ for the rectangular columnar mesophase and $Z=2$ for the hexagonal columnar mesophase. We would like to emphasize that a precise calculation of $Z$ is not possible without a $\pi-\pi$ reflex and the exact density. However, in agreement with previous studies ${ }^{79-83}$ the columnar stratum $h$ was obtained from the halo reflection in the WAXS in those cases, where the $\pi-\pi$ reflection was not visible, and a density $\rho$ of $1 \mathrm{~g} / \mathrm{cm}^{3}$ may be assumed for an organic material containing no metals or heavy elements. ${ }^{79,84-86}$ 
Table 4. XRD Data of Symmetric Diazafluorenones DAF(OCn)6, BrDAF(OC14) and $(\mathrm{C14O})_{3}$ DAF(OC14)

\begin{tabular}{|c|c|c|c|c|c|}
\hline Compound & Mesophase & $\begin{array}{l}\text { Lattice } \\
\text { parameter / } \AA\end{array}$ & $\begin{array}{l}d \text { values / } \AA \\
\text { exp. (calc.) }\end{array}$ & $\begin{array}{l}\text { Miller } \\
\text { Indices }\end{array}$ & $Z$ \\
\hline $\mathrm{DAF}(\mathrm{OC} 8)_{6}$ & $\begin{array}{l}\mathrm{Col}_{\mathrm{h}} \text { at } 95^{\circ} \mathrm{C} \\
\text { p6mm }\end{array}$ & $a=29.5$ & $\begin{array}{l}25.5 \\
4.5\end{array}$ & $\begin{array}{l}\text { (10) } \\
\text { (Halo) }\end{array}$ & 2 \\
\hline $\mathrm{DAF}(\mathrm{OC10})_{6}$ & $\begin{array}{l}\mathrm{Col}_{\mathrm{h}} \text { at } 93^{\circ} \mathrm{C} \\
\text { p6mm }\end{array}$ & $a=31.9$ & $\begin{array}{l}27.6 \\
4.5\end{array}$ & $\begin{array}{l}(10) \\
\text { (Halo) }\end{array}$ & 2 \\
\hline $\mathrm{DAF}(\mathrm{OC12})_{6}$ & $\begin{array}{l}\mathrm{Col}_{\mathrm{h}} \text { at } 93^{\circ} \mathrm{C} \\
p 6 m m\end{array}$ & $a=34.1$ & $\begin{array}{l}29.6 \\
17.2(17.1) \\
4.6\end{array}$ & $\begin{array}{l}(10) \\
(11) \\
\text { (Halo) }\end{array}$ & 2 \\
\hline $\mathrm{DAF}(\mathrm{OC14})_{6}$ & $\begin{array}{l}\mathrm{Col}_{\mathrm{h}} \text { at } 85^{\circ} \mathrm{C} \\
p 6 m m\end{array}$ & $a=36.1$ & $\begin{array}{l}31.3 \\
18.0(18.1) \\
15.7(15.6) \\
4.6\end{array}$ & $\begin{array}{l}(10) \\
(11) \\
(20) \\
\text { (Halo) }\end{array}$ & 2 \\
\hline & $\begin{array}{l}\mathrm{Col}_{\mathrm{rd}} \text { at } 49^{\circ} \mathrm{C} \\
p 2 g g\end{array}$ & $\begin{array}{l}a=59.5 \\
b=40.5\end{array}$ & $\begin{array}{l}33.3(33.3) \\
19.1(19.1) \\
16.6(16.6) \\
14.9(14.6) \\
11.1(11.1) \\
10.0(10.0) \\
8.5(8.3) \\
7.8(7.8) \\
4.6\end{array}$ & $\begin{array}{l}(11) \\
(12) \\
(22) \\
(40) \\
(33) \\
(14) \\
(44) \\
(25) \\
\text { (Halo) }\end{array}$ & 4 \\
\hline & $\begin{array}{l}\mathrm{Col}_{\text {ro }} \text { at } 16^{\circ} \mathrm{C} \\
p 2 g g\end{array}$ & $\begin{array}{l}a=58.8 \\
b=40.3\end{array}$ & $\begin{array}{l}33.0(33.0) \\
19.0(19.0) \\
16.5(16.5) \\
14.7(14.4) \\
11.0(11.0) \\
9.9(9.9) \\
8.5(8.3) \\
7.7(7.8) \\
4.3 \\
4.2\end{array}$ & $\begin{array}{l}(11) \\
(12) \\
(22) \\
(40) \\
(33) \\
(14) \\
(44) \\
(25) \\
(\text { Halo }) \\
(\pi-\pi)\end{array}$ & 4 \\
\hline $\mathrm{DAF}(\mathrm{OC16})_{6}$ & $\begin{array}{l}\mathrm{Col}_{\mathrm{h}} \text { at } 81^{\circ} \mathrm{C} \\
p 6 m m\end{array}$ & $a=38.2$ & $\begin{array}{l}33.1 \\
19.0(19.1) \\
16.6(16.5) \\
4.6\end{array}$ & $\begin{array}{l}(10) \\
(11) \\
(20) \\
\text { (Halo) }\end{array}$ & 2 \\
\hline & $\begin{array}{l}\mathrm{Col}_{2}{ }^{a} \\
\mathrm{Col}_{1}{ }^{a}\end{array}$ & & & & \\
\hline BrDAF(OC14) & $\begin{array}{l}\text { SmA at } \\
143^{\circ} \mathrm{C}\end{array}$ & & $\begin{array}{l}36.8 \\
4.3\end{array}$ & $\begin{array}{l}(001) \\
(\text { Halo })\end{array}$ & \\
\hline$(\mathrm{C} 140)_{3} \mathrm{DAF}(\mathrm{OC14})$ & $\begin{array}{l}\mathrm{Col}_{\mathrm{h}} \text { at } 65^{\circ} \mathrm{C} \\
p 6 \mathrm{~mm}\end{array}$ & $a=40.3$ & $\begin{array}{l}34.9 \\
4.4\end{array}$ & $\begin{array}{l}(10) \\
\text { (Halo) }\end{array}$ & 3 \\
\hline
\end{tabular}

Molecular modelling of diazafluorenone DAF(OC14)6 employing AVOGADRO software $^{87}$ yielded a calculated molecular lengths of $53 \AA$. Thus each disk within the hexagonal lattice 
consists of two molecules oriented antiparallel in order to compensate the dipole moment and the alkoxy side chains are strongly interdigitated in the $\mathrm{Col}_{\mathrm{h}}$ phase. Also in the $\mathrm{Col}_{\mathrm{r}}$ lattice with $p 2 g g$ symmetry each disk consists of two diazafluorenone molecules (Figure 11).
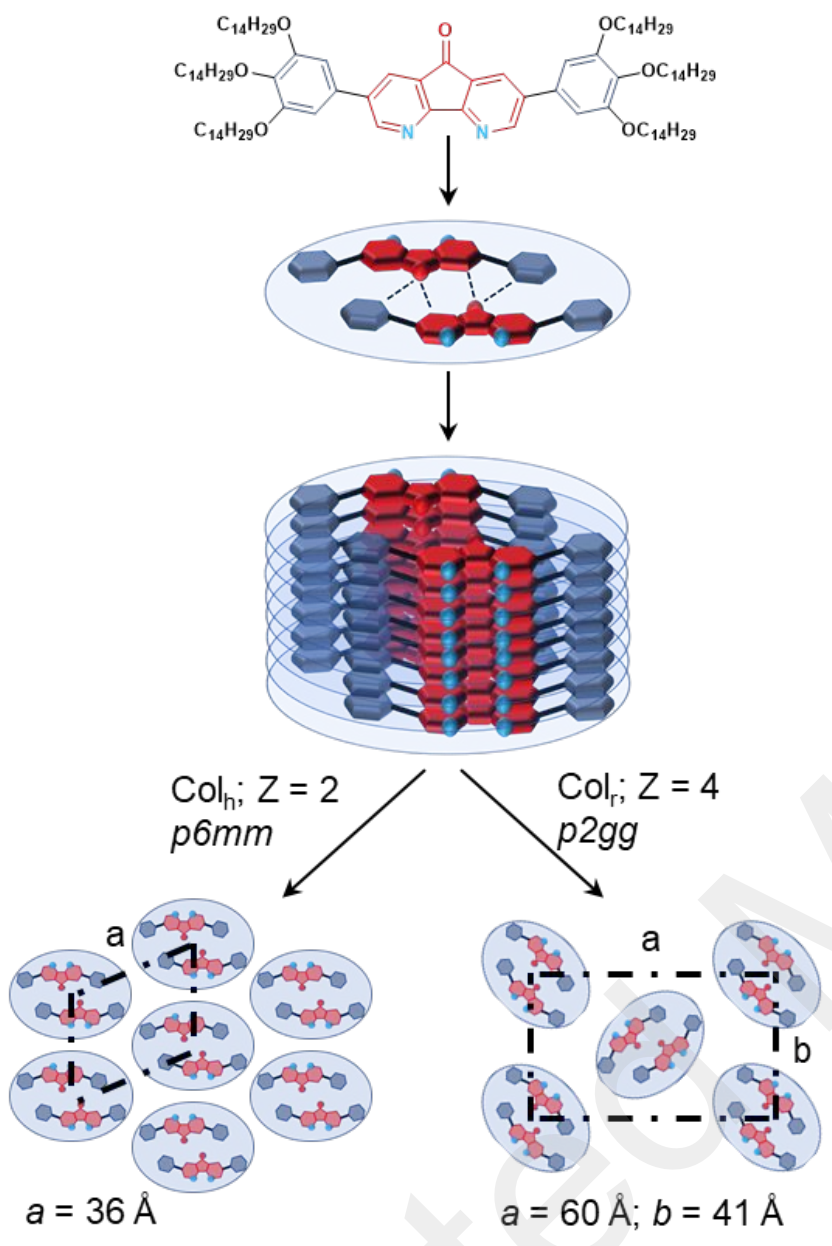

Figure 11. Proposed packing model of the high temperature hexagonal columnar and low temperature rectangular columnar phases, respectively, for $\mathbf{D A F}(\mathbf{O C 1 4})_{6}$ based on X-ray crystal structure data.

Symmetrical diazafluorenones DAF(OCn) 2 and DAF(OCn) $)_{6}$ with two or six alkyloxy side chains in the periphery provided nematic, smectic and columnar mesophases, respectively, however, their high clearing points may limit possible applications. To overcome this problem, the unsymmetrical derivative (C14O) ${ }_{3} \mathbf{D A F}(\mathbf{O C 1 4})$ was prepared (Scheme 1). According to DSC studies $(\mathbf{C 1 4 0})_{3} \mathbf{D A F}(\mathbf{O C 1 4})$ showed an enantiotropic mesophase that underwent transition to isotropic liquid at $80^{\circ} \mathrm{C}$ (Figure 12c), and thus a reduction of the clearing point as compared to the symmetrical counterparts described above. 

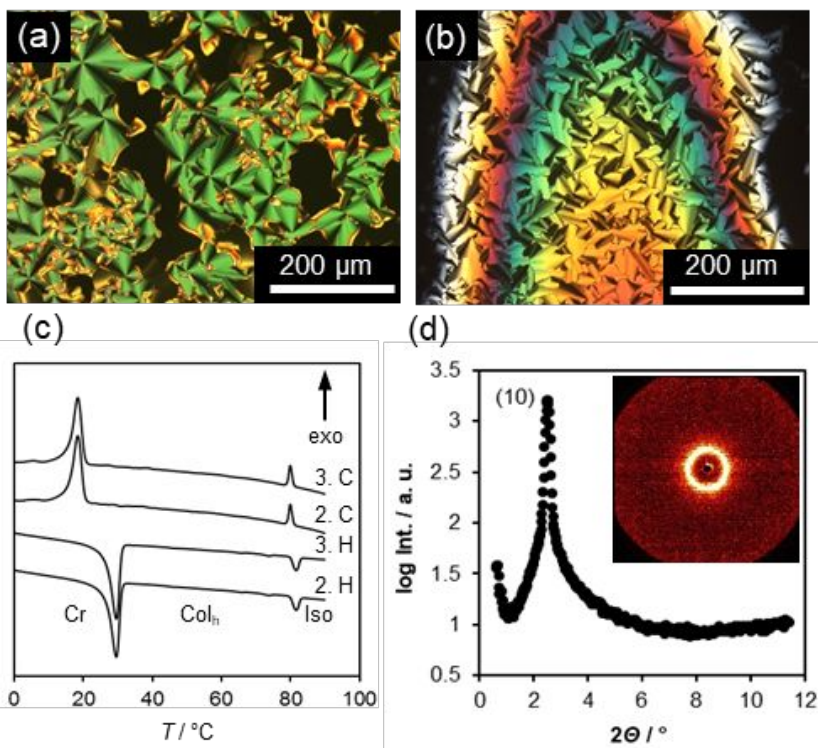

(d)

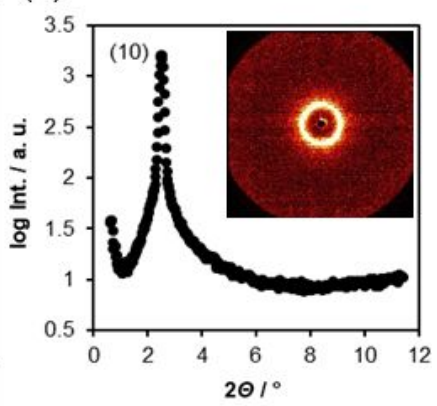

Figure 12. (a) POM image of (C140) $)_{3} \mathrm{DAF}(\mathbf{O C 1 4})$ at $75^{\circ} \mathrm{C}$ and (b) at $59^{\circ} \mathrm{C}$ upon cooling from the isotropic liquid (cooling rate $10 \mathrm{~K} \mathrm{~min}^{-1}$, magnification $\times 100$ ). (c) DSC curves (heating/ cooling rate $5 \mathrm{~K} \mathrm{~min}^{-1}, 2^{\text {nd }}$ and $3^{\text {rd }}$ heating: 2 . H, 3. H; $2^{\text {nd }}$ and $3^{\text {rd }}$ cooling: $2 . \mathrm{C}, 3$. C). (d) SAXS profile and the corresponding diffraction pattern (inset) at $65^{\circ} \mathrm{C}$.

Under the POM $(\mathbf{C 1 4 O})_{3} \mathbf{D A F}(\mathbf{O C 1 4})$ formed fan-shaped textures at $59^{\circ} \mathrm{C}$ and focal conic textures with homeotropic domains at $75^{\circ} \mathrm{C}$ (Figure 12a,b) which are typical for columnar mesophases. In the SAXS profile only the (10) reflection could be detected, and at wide angles a broad halo around $4.4 \AA$ (Figure 12d). Although the mesophase could not be definitely assigned based on these XRD data, we assume a $\mathrm{Col}_{\mathrm{h}}$ phase with $\mathrm{p} 6 \mathrm{~mm}$ symmetry (Table 4) due to the observed POM textures and structural similarity in comparison with the other DAF derivatives. The number of molecules per unit cell $Z$ was calculated to be $Z=3$. Thus three molecules self-assemble to a discotic structure, stacking in columns which organize into a hexagonal lattice. Bromide BrDAF(OC14) displayed enantiotropic mesomorphism. Upon second heating the mesophase ranged from 151 to $193^{\circ} \mathrm{C}$, and under POM a texture typical for a SmA mesophase was observed, that was confirmed by XRD studies (Figures S4 and S16). The measured $d$ layer spacing of $36.8 \AA$ corresponds to the molecular length, indicating SmA monolayers. 
UV/Vis and luminescence spectroscopy. Selected diazafluorenones DAF(OCn $)_{2}(n=$ 6,12,16), $\mathbf{D A F}(\mathbf{O C 1 2})_{4}$ and $\mathbf{D A F}(\mathbf{O C 1 2})_{6}$ were investigated by UV/Vis and luminescence spectroscopy in chloroform solution (Table 5, Figure 13).
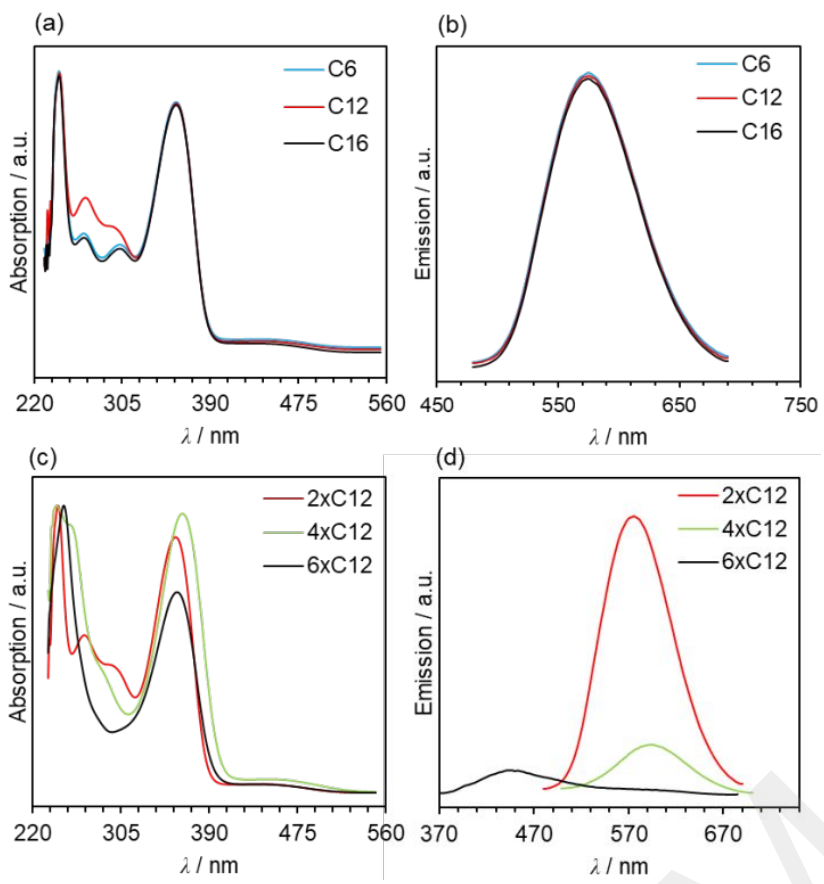

Figure 13. Normalized absorption (a) and emission spectra (b) of DAF(OCn $)_{2}$ differing in the chain lengths (excitation wavelength $\lambda_{\mathrm{exc}}=357 \mathrm{~nm}$ ). Absorption (c) and emission spectra (d) of DAF(OC12) $)_{\mathbf{m}}$ differing in the total number $m$ of alkoxy chains. All spectra were measured in $\mathrm{CHCl}_{3}$ (conc. $10^{-5} \mathrm{~mol} \mathrm{~L}^{-1}, \lambda_{\text {exc }}=357 \mathrm{~nm}\left(\mathbf{D A F}(\mathbf{O C 1 2})_{2}\right), 363 \mathrm{~nm}\left(\mathbf{D A F}(\mathbf{O C 1 2})_{4}\right)$, $356 \mathrm{~nm}\left(\mathbf{D A F}(\mathbf{O C 1 2})_{6}\right)$.

Diazafluorenones $\mathbf{D A F}(\mathbf{O C n})_{2}$ carrying two peripheral alkoxy chains exhibited a strong absorption band at $358 \mathrm{~nm}$ irrespective of the chain lengths $\mathrm{n}$ (Figure 13a). The broad weak band at $440 \mathrm{~nm}$ was responsible for the orange color of the solution. The emission spectra of DAF(OCn $)_{2}$ are shown in Figure 13b. The excitation wavelength was fixed at the absorption maximum $\left(\lambda_{\text {exc }}=357 \mathrm{~nm}\right)$. A pronounced orange luminescence emission band at $\lambda=575 \mathrm{~nm}$ was observed, resulting in a large Stokes shift of $10620 \mathrm{~cm}^{-1}$ (Figure 13b, Table 5). Neither emission intensity nor Stokes shift were affected by the chain lengths, which is in good agreement with previous results by $\mathrm{Li}^{88}$ and Goncalves. ${ }^{89}$ 
However, the number of alkoxy chains in the periphery of the diazafluorenones considerably influenced absorption and emission spectra, as shown for $\mathbf{D A F}(\mathbf{O C 1 2})_{\mathbf{m}}(\mathrm{m}=2,4,6)$ (Figure 13c,d). The absorption maximum was only slightly red-shifted with increasing number of side chains from $358 \mathrm{~nm}$ for $\mathbf{D A F}(\mathbf{O C 1 2})_{2}$ to 364 and $359 \mathrm{~nm}$ for $\mathbf{D A F}(\mathbf{O C 1 2})_{4}$ and $\mathbf{D A F}(\mathbf{O C 1 2})_{6}$, respectively, along with minor changes of the relative intensities (Figures 13c). In contrast, fluorescence wavelength and intensity were strongly impacted by the substitution pattern (Figure 13d).

Table 5. Absorption and Emission Data of DAF(OCn $)_{2}, \mathrm{DAF}(\mathrm{OC12})_{4}$ and DAF(OC12 $)_{6}$ in $\mathrm{CHCl}_{3}$ (conc. $\mathbf{1 0}^{-5} \mathrm{~mol} \mathrm{~L}^{-1}$ )

\begin{tabular}{|c|c|c|c|c|}
\hline compound & $\begin{array}{l}\lambda_{\max , \mathrm{abs}} / \\
\mathrm{nm}\left(\mathrm{cm}^{-1}\right)\end{array}$ & $\begin{array}{l}\varepsilon_{\max } / \\
10^{4} \mathrm{~L} \mathrm{~mol}^{-1} \mathrm{~cm}^{-1}\end{array}$ & $\begin{array}{l}\lambda_{\max , \mathrm{fl}} / \\
\mathrm{nm}\left(\mathrm{cm}^{-1}\right)\end{array}$ & $\begin{array}{l}\text { Stokes shift/ } \\
\mathrm{cm}^{-1}\end{array}$ \\
\hline \multirow[t]{4}{*}{$\mathrm{DAF}(\mathrm{OC6})_{2}$} & $268(37313)$ & 2.16 & \multirow{4}{*}{575 (17391) } & \multirow{4}{*}{10620} \\
\hline & $303(33003)$ & 1.95 & & \\
\hline & $357(28011)$ & 4.66 & & \\
\hline & $440(22727)$ & 0.16 & & \\
\hline \multirow[t]{4}{*}{$\mathrm{DAF}(\mathrm{OC} 12)_{2}{ }^{a}$} & $270(37037)$ & 2.96 & \multirow[t]{4}{*}{$575(17391)$} & \multirow[t]{4}{*}{10542} \\
\hline & 300 (33333) & 2.34 & & \\
\hline & 358 (27932) & 4.79 & & \\
\hline & $440(22727)$ & 0.16 & & \\
\hline \multirow[t]{4}{*}{$\mathrm{DAF}(\mathrm{OC} 16)_{2}$} & $268(37313)$ & 2.27 & \multirow[t]{4}{*}{$575(17391)$} & \multirow[t]{4}{*}{10542} \\
\hline & 303 (33003) & 2.05 & & \\
\hline & 358 (27932) & 4.88 & & \\
\hline & $440(22727)$ & 0.18 & & \\
\hline \multirow[t]{3}{*}{$\mathrm{DAF}(\mathrm{OC12}){ }_{4}^{b}$} & $255(39215)$ & 4.39 & \multirow[t]{3}{*}{$594(16835)$} & \multirow[t]{3}{*}{10637} \\
\hline & $364(27472)$ & 4.58 & & \\
\hline & $445(22471)$ & 0.22 & & \\
\hline \multirow[t]{3}{*}{$\mathrm{DAF}(\mathrm{OC} 12)_{6}{ }^{c}$} & $250(40000)$ & 7.50 & \multirow[t]{3}{*}{$446(22422)$} & \multirow[t]{3}{*}{5433} \\
\hline & $359(27855)$ & 5.24 & & \\
\hline & $438(22831)$ & 0.22 & & \\
\hline
\end{tabular}

${ }^{a}$ Excitation wavelength $357 \mathrm{~nm} .{ }^{b}$ Excitation wavelength $363 \mathrm{~nm} .{ }^{c}$ Excitation wavelength $356 \mathrm{~nm}$.

A shift of the wavelength of the emission maximum from $\lambda=575 \mathrm{~nm}$ to $594 \mathrm{~nm}$ was observed when going from DAF(OC12) $)_{2}$ to $\mathbf{D A F}(\mathbf{O C 1 2})_{4}$, resulting in a Stokes shift for DAF(OC12) $)_{4}$ larger than that of DAF(OC12) $\left(10637 \mathrm{~cm}^{-1}\right.$ vs. $\left.10542 \mathrm{~cm}^{-1}\right)$. More pronounced is the decrease of emission band intensities. In comparison to the orange emission of 
DAF(OC12) ${ }_{2}$, derivative DAF(OC12) ${ }_{4}$ with four dodecyl chains displayed a much weaker orange emission and $\mathbf{D A F}(\mathbf{O C 1 2})_{6}$ with six dodecyl chains showed a weak blue emission (Figure 13d). The weak blue emission and small stokes shift in the latter case might be imparted to reabsorption phenomena. In order to study this decrease of the emission intensity for $\mathbf{D A F}(\mathbf{O C 1 2})_{4}$ and $\mathbf{D A F}(\mathbf{O C 1 2})_{6}$, concentration dependent emission spectra were recorded (Figure 14).
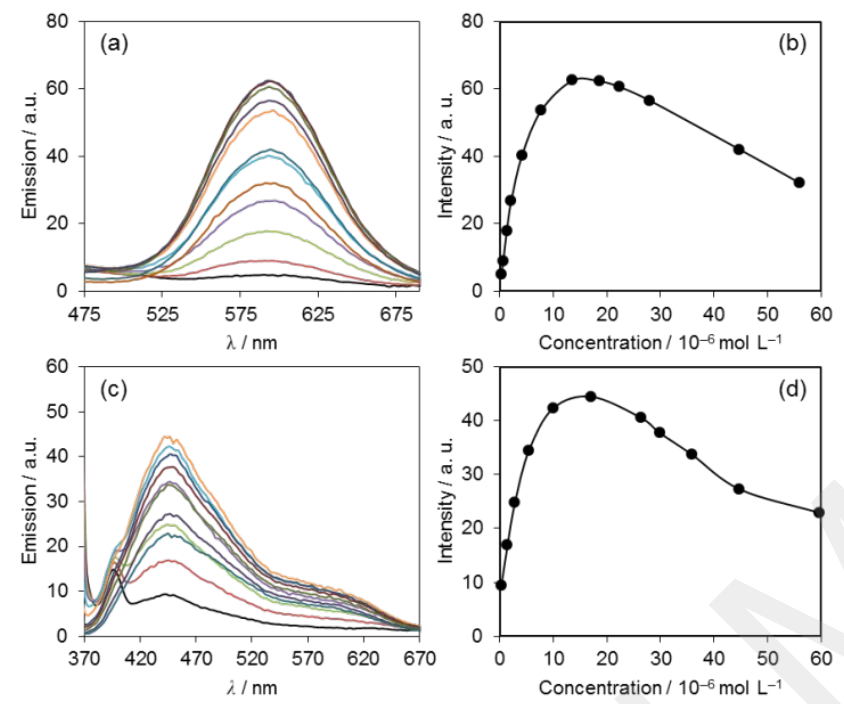

Figure 14. Concentration dependent emission spectra of $\mathbf{D A F}(\mathbf{O C 1 2})_{4}(\mathrm{a})$ and $\mathrm{DAF}(\mathbf{O C 1 2})_{6}$ (c). Emission intensity plotted versus concentration at the emission maximum $594 \mathrm{~nm}$ for DAF(OC12) 4 (b) and $446 \mathrm{~nm}$ for $\mathbf{D A F}(\mathbf{O C 1 2})_{6}(\mathrm{~d})$.

As can be seen from Figures $14 \mathrm{~b}$, d at concentrations below $1.4 \cdot 10^{-5} \mathrm{~mol} \mathrm{~L}^{-1}$ for DAF(OC12) and $1.7 \cdot 10^{-5} \mathrm{~mol} \mathrm{~L}^{-1}$ for $\mathbf{D A F}(\mathbf{O C 1 2})_{6}$, respectively, an increase of the emission intensity was observed with increasing concentration. In the case of $\mathbf{D A F}(\mathbf{O C 1 2})_{6}$, the emission maximum additionally shifted from $396 \mathrm{~nm}\left(3.0 \cdot 10^{-7} \mathrm{~mol} \mathrm{~L}{ }^{-1}\right)$ to $446 \mathrm{~nm}$ at higher concentrations (Figure 14c, see also Figure S20), presumably due to electronic effects of the diazafluorenone core. However, the emission intensities are still very low as compared to $\mathbf{D A F}(\mathbf{O C 1 2})_{2}$. At concentrations above $1.4 \cdot 10^{-5} \mathrm{~mol} \mathrm{~L}^{-1}$ and $1.7 \cdot 10^{-5} \mathrm{~mol} \mathrm{~L}^{-1}$, respectively, the intensity decreased for both $\mathbf{D A F}(\mathbf{O C 1 2})_{4}$ and $\mathbf{D A F}(\mathbf{O C 1 2})_{6}$, resulting from aggregation-caused quenching of fluorescence..$^{90}$ 
In the solid state derivative $\mathbf{D A F}(\mathbf{O C 1 2})_{2}$ showed a broad emission profile ranging from 550 to $750 \mathrm{~nm}$ with a maximum at $596 \mathrm{~nm}$ and two shoulder peaks around 650 and $680 \mathrm{~nm}$ as well as a minor red shift in contrast to the emission profile in solution (Figure 15a). The shoulder peaks might originate from emission in excited vibrational levels of $S_{0}$, which do not exist in solution due to solvent quenching effects.

(a)

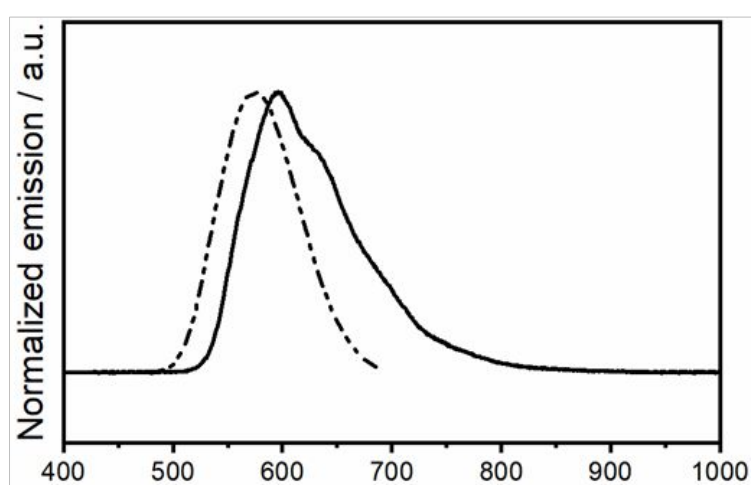

(b)

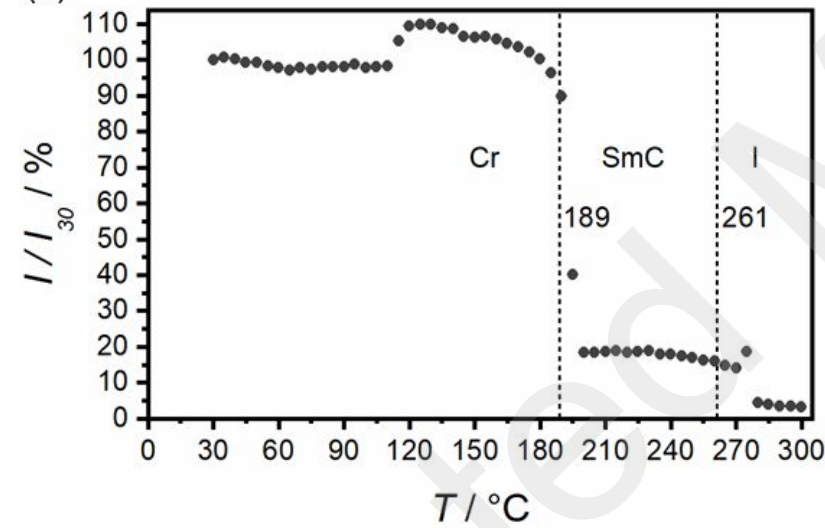

Figure 15. (a) Comparison of normalized emission spectra of $\mathbf{D A F}(\mathbf{O C 1 2})_{2}$ at ambient temperature in solution $\left(\mathrm{CHCl}_{3}\right.$, dashed dots $)$ and in the solid state. Solid state emission spectra were recorded by POM $\left(\lambda_{\text {exc }}=375 \mathrm{~nm}\right)$ with a connected photo detector. (b) Emission intensity evolution of $\mathbf{D A F}(\mathbf{O C 1 2})_{2}$ with temperature. The sample was heated to the isotropic liquid and spectra were recorded upon cooling in intervals of $5 \mathrm{~K}$ (cooling rate $1 \mathrm{~K} \mathrm{~min}^{-1}$ ). The intensity maxima $(I)$ at given temperatures were divided by the maximum intensity at $30^{\circ} \mathrm{C}$ $\left(I_{30}\right)$. Transition temperatures (dotted lines) are taken from DSC data in Table 2. The temperature dependent fluorescence spectra are depicted in Figure S19 in the Supporting Information.

The temperature dependent emission spectrum of $\mathbf{D A F}(\mathbf{O C 1 2})_{2}$ revealed a very low intensity in the isotropic liquid as compared to the $I_{30}$ value due to non-radiative deactivation of the excited state at high temperatures. Surprisingly, the intensity increased at the phase transition 
to the SmC phase and further increased strongly at the SmC-to-Cr transition (Figure 15b). This effect might be explained by an increase in rigidity in the corresponding phases, leading to less non-radiative deactivation and thus resulting in a higher emission intensity. Another remarkable feature of the bulk luminescence spectra of $\mathbf{D A F}(\mathbf{O C 1 2})_{2}$ is the observed effect, that the luminescence intensity does not change instantaneously at the melting and clearing temperature. This effect is particularly visible at the clearing transition, where the luminescence intensity of the $\mathrm{SmC}$ phase persists although the clearing point has been surpassed by already $10 \mathrm{~K} \cdot{ }^{91}$ This behavior might be rationalized by the presence of pretransitional aggregates. ${ }^{92,93}$ In other words, the isotropic phase seems to contain some aggregates with lamellar order contributing to the higher luminescence intensity.

\section{- CONCLUSION}

We have developed for the first time luminescent liquid crystals $\mathbf{D A F}(\mathbf{O C n})_{2}, \mathbf{D A F}(\mathbf{O C n})_{4}$, DAF(OCn) 6 based on 4,5-diazafluoren-9-one. Their self-assembly behavior in the mesophase was strongly controlled by both chain lengths and total number of side chains. All members of the calamitic series $\mathbf{D A F}(\mathbf{O C n})_{2}(\mathrm{n}=6-16)$ formed enantiotropic $\mathrm{SmC}$ phases with broad phase widths up to $73 \mathrm{~K}$ demonstrating the potential of the diazafluorenone core as a smectic C promoting scaffold, that complements previous work on fluorenones. ${ }^{4-13}$ Additionally, short chain members $\mathbf{D A F}(\mathbf{O C 6})_{2}, \mathbf{D A F}(\mathbf{O C} 7)_{2}, \mathbf{D A F}(\mathbf{O C 8})_{2}$ displayed a nematic phase whose temperature range and stability decreased with increasing chain lengths. Chain length dependent differences were also found in the solid state packing behavior. Although direct correlations between solid state and mesophase structures have to be considered with great care, a comparison of the crystal structures of DAF $(\mathbf{O C 6})_{2}, \mathrm{DAF}(\mathrm{OC} 8)_{2}, \mathrm{DAF}(\mathrm{OC} 9)_{2}$, and DAF(OC12 $)_{2}$ revealed for the latter homologues that van der Waals interactions strongly favor a linear alltrans conformation with increasing chain lengths and a lamellar arrangement, that corresponds with the "smectic C only" mesomorphism. In contrast, interdigitation of the alkoxy 
chains in the shorter chain homologues $\mathbf{D A F}(\mathbf{O C 6})_{2}$ and $\mathbf{D A F}(\mathbf{O C} 8)_{2}$ is less pronounced due to smaller van der Waals interactions and out of plane orientation, which results in coexisting nematic and smectic $C$ phases. In addition, the crystallographic data suggest that the $\pi(\mathrm{C}-$ $\mathrm{H}) \cdots \mathrm{N}$ bond induced dimers not only stabilize the crystal packing but also enforce the stability of the $\mathrm{SmC}$ phase resulting in a temperature range of up to $74 \mathrm{~K}$.

Whereas the attachment of four side chains in $\mathbf{D A F}(\mathbf{O C n})_{4}$ led to complete loss of mesomorphism, the phasmidic molecular structure in combination with the lateral dipole moment promoted enantiotropic $\mathrm{Col}_{\mathrm{h}}$ mesophases with a minimum chain length of $\mathrm{C} 8$ (phase widths $\leq 12 \mathrm{~K})$ for the series $\mathbf{D A F}(\mathbf{O C n})_{6}$. Besides a high temperature $\mathrm{Col}_{\mathrm{h}}$ phase $\mathbf{D A F}(\mathbf{O C 1 4})_{6}$ and DAF(OC16) ${ }_{6}$ displayed two rectangular columnar phases $\mathrm{Col}_{\mathrm{ro}}$ and $\mathrm{Col}_{\mathrm{rd}}$ at lower temperatures (phase widths $\leq 43 \mathrm{~K}$ ). The packing models based on XRD data suggested that the $\mathrm{C}_{2^{-}}$ symmetrical $\pi(\mathrm{C}-\mathrm{H}) \cdots \mathrm{N}$ bond induced dimers found in the X-ray crystal structure persisted both in the $\mathrm{Col}_{\mathrm{r}}$ and $\mathrm{Col}_{\mathrm{h}}$ mesophase.

According to UV/Vis spectra of selected derivatives in solution neither chain lengths nor total number of side chains had any influence on the absorption behavior of the diazafluorenones. In contrast, luminescence spectra showed different trends. In the case of DAF $(\mathbf{O C n})_{2}$, in solution emission wavelengths and intensity were invariable with respect to the chain length $\mathrm{n}$. However, emission intensities decreased significantly when more than two alkoxy side chains were grafted to the core. For example, phasmidic DAF(OC12) 6 may be able to form strong H-aggregates due to van der Waals interactions of alkoxy side chains, $\pi-\pi$ interaction and Coulomb forces of the diazafluorenone core.

Investigation of the bulk emission properties of $\mathbf{D A F}(\mathbf{O C 1 2})_{2}$ at various temperatures showed that the diazafluorenone $\mathbf{D A F}(\mathbf{O C 1 2})_{2}$ was non-emissive in the isotropic liquid. In the SmC phase an emission was detected, which increased significantly upon cooling into the crystalline solid, revealing aggregation-induced emission (AIE) behavior. ${ }^{94,95}$ The AIE- 
induced fluorescence enhancement is not centered at the phase transition temperature, but at higher temperature, indicating that the extent of aggregation needed for fluorescence enhancement is lower than that required for mesophase formation. ${ }^{96}$ The results demonstrate that both self-assembly and emission behavior of the diazafluorenone scaffold can be manipulated by tailoring of the side chains providing access to both calamitic and discotic (columnar) mesogens.

For an unsymmetrical derivative $(\mathbf{C 1 4 O})_{3} \mathbf{D A F}(\mathbf{O C 1 4})$ we demonstrate that the clearing transition could be decreased while the temperature range of the $\mathrm{Col}_{\mathrm{h}}$ phase increased at the expense of the $\mathrm{Col}_{\mathrm{r}}$ phases. Following recent precendence by Williams ${ }^{97}$ such symmetry breaking might be a useful strategy for the calamitic series $\mathbf{D A F}(\mathbf{O C n})_{2}$ to reduce clearing transitions significantly without compromising the $\mathrm{SmC}$ to $\mathrm{N}$ transition. Future work is necessary to exploit this in detail.

In summary, we not only developed new calamitic fluorophores and phasmidic mesogens based on diazafluorenone, but also provide some insight into the mesomorphic self assembly of liquid crystalline compounds on the basis of solid state structural data. We believe that this tool might facilitate the design of other calamitic liquid crystals as well.

\section{- ASSOCIATED CONTENT}

* Supporting Information

The Supporting Information is available free of charge on the ACS Publications website at DOI:

General Information, Synthesis of DAF(OCn) $)_{\mathbf{m}}$, DSC, POM and XRD studies, ORTEP plot of DAF(OC12) 2 as well as ${ }^{1} \mathrm{H}$ and ${ }^{13} \mathrm{C}$ NMR spectra of all new derivatives (PDF)

\section{Accession Codes}

CCDC $1896543,1896545,1896547,1896549$ contain the supplementary crystallographic data for this paper. These data can be obtained free of charge via 
www.ccdc.cam.ac.uk/data_request/cif, or by emailing data_request@ccdc.cam.ac.uk, or by contacting The Cambridge Crystallographic Data Centre, 12 Union Road, Cambridge CB2 1EZ, UK; fax: +44 1223336033.

\section{a AUTHOR INFORMATION}

\section{Corresponding Author}

*E-mail: sabine.laschat@oc.uni-stuttgart.de.

\section{ORCID}

Sabine Laschat: 0000-0002-1488-3903

\section{Notes}

The authors declare no competing financial interest.

\section{- ACKNOWLEDGEMENT}

Generous financial support by the Deutsche Forschungsgemeinschaft (shared instrumentation grant HBFG INST 41/815-1 FUGG, DFG-ANR joint project SNAPSTER), the Deutsche Akademische Austauschdienst (PPP Procope program PLISE), the Fonds der Chemischen Industrie, the Bundesministerium für Bildung und Forschung (shared instrumentation grant 01 RI05177), the Carl-Schneider Stiftung Aalen and the Ministerium für Wissenschaft, Forschung und Kunst des Landes Baden-Württemberg is gratefully acknowledged.

\section{- REFERENCES}

(1) Goodby, J. W. Design and synthesis of smectic liquid crystals. In Handbook of Liquid Crystals, $2^{\text {nd }}$ ed., Vol. 4; Goodby, J. W., Collings, P. J., Kato, T., Tschierske, C., Gleeson, H. F., Raynes, P., Eds.; Wiley-VCH: Weinheim, 2014; pp 3-41.

(2) Goodby, J. W.Structures and properties of smectic liquid crystals. In Handbook of Liquid Crystals, $2^{\text {nd }}$ ed., Vol. 4; Goodby, J. W., Collings, P. J., Kato, T., Tschierske, C., Gleeson, H. F., Raynes, P., Eds.; Wiley-VCH: Weinheim, 2014; pp 43-68. 
(3) Goodby, J. W.; Mandle, R. J.; Davis, E. J.; Zhong, T.; Cowling, S. J. What makes a liquid crystal? The effect of free volume on soft matter. Liq. Cryst. 2015, 42, 593-622.

(4) Biering, A.; Demus, D.; Gray, G. W.; Sackmann, H. The Classification of the Liquid Crystalline Modificatons in some Homologous Series. Mol. Cryst. Liq. Cryst. 1974, 28, 275292.

(5) Sakashita, H.; Komori, S.; Kamon, K.; Terauchi, H.; Shimizu, Y.; Kusabayashi, S. XRay Diffraction Study on the Reentrant Smectic A Phase in a Binary Liquid Crystal System. Mol. Cryst. Liq. Cryst. 1987, 149, 49-60.

(6) Shimizu, S.; Kusabayashi, S. A N-S $\mathrm{S}_{\mathrm{A}}-\mathrm{S}_{\mathrm{C}}-\mathrm{S}_{\mathrm{A}}$ Reentrant Phenomenon by a Binary Mixture of Dodecyloxy and Tridecyloxy Homologues of 2-(4-Alkoxybenzylideneamino) Fluorenones. Mol. Cryst. Liq. Cryst. 1986, 3, 121-125.

(7) Ivanov, A. V.; Lyakhov, S. A.; Yarkova, M. Y.; Galatina, A. I.; Mazepa, A. V. Synthesis and Liquid Crystal Properties of 2,7-Dialkoxy-9-fluorenones. Russ. J. Gen. Chem. 2002, 72, 1435-1438.

(8) Harjung, M. D.; Schubert, C. P. J.; Knecht, F.; Porada, J. H.; Lemieux, R. P.; Giesselmann, F. New amphiphilic materials showing the lyotropic analogue to the thermotropic smectic C* liquid crystal phase. J. Mater. Chem. C 2017, 5, 7452-7457.

(9) McCubbin, J. A.; Tong, X.; Wang, R.; Zhao, Y.; Snieckus, V.; Lemieux, R. P. Directed Metalation Route to Ferroelectric Liquid Crystals with a Chiral Fluorenol Core: The Effect of Restricted Rotation on Polar Order. J. Am. Chem. Soc. 2004, 126, 1161-1167.

(10) McCubbin, A. J.; Snieckus, V.; Lemieux, R. P. Ferroelectric liquid crystals with fluoro- and aza-fluorenone cores: the effect of stereo-polar coupling. Liq. Cryst. 2005, 32, $1195-1203$.

(11) McCubbin, J. A.; Tong, X.; Zhao, Y.; Snieckus, V.; Lemieux, R. P. Directed Metalation-Cross Coupling Route to Ferroelectric Liquid Crystals with a Chiral Fluorenol 
Core: The Effect of Intermolecular Hydrogen Bonding on Polar Order. Chem. Mater. 2005, $17,2574-2581$.

(12) Lincker, F.; Attias, A.-J.; Mathevet, F.; Heinrich, B.; Donnio, B.; Fave, J.-L.; Rannou, P.; Demadrille, R. Influence of polymorphism on charge transport properties in isomers of fluorenone-based liquid crystalline semiconductors. Chem. Commun. 2012, 48, 3209-3211. (13) Lincker, F.; Heinrich, B.; De Bettignies, R.; Rennou, P.; Pécaut, J.; Grévin, B.; Pron, A.; Donnio, B.; Demadrille R. Fluorenone core donor-acceptor-donor p-conjugated molecules end-capped with dendritic oligo(thiophene)s: synthesis, liquid crystalline behaviour, and photovoltaic applications. J. Mater. Chem. 2011, 21, 5238-5247.

(14) Eckhard, I. F.; Summers, L. A. 4,5-Diazafluoren-9-one from the oxidation of 1,10phenanthroline by permanganate. Aust. J. Chem. 1973, 26, 2727-2728.

(15) Campbell, A. N.; White, P. B.; Guzei, I. A.; Stahl, S. S. Allylic C-H Acetoxylation with a 4,5-Diazafluorenone-Ligated Palladium Catalyst: a Ligand-Based Strategy To Achieve Aerobic Catalytic Turnover. J. Am. Chem. Soc. 2010, 132, 15116-15119.

(16) Diao, T.; Wadzinski, T. J.; Stahl, S. S. Direct aerobic $\alpha, \beta$-dehydrogenation of aldehydes and ketones with a Pd(TFA)/4,5-diazafluorenone catalyst. Chem. Sci. 2012, 3, 887891.

(17) Gao, W.; He, Z.; Qian, Y.; Zhao, J.; Huang, Y. General palladium-catalyzed aerobic dehydrogenation to generate double bonds. Chem. Sci. 2012, 3, 883-886.

(18) Vasseur, A.; Laugel, C.; Harakat, D.; Muzart, J.; Le Bras, J. Ligand-Promoted Reactivity of Alkenes in Dehydrogenative Heck Reactions of Furans and Thiophenes. Eur. J. Org. Chem. 2015, 944-948.

(19) Piotrowicz, M.; Zakrzewski, J. Aerobic Dehydrogenative Heck Reaction of Ferrocene

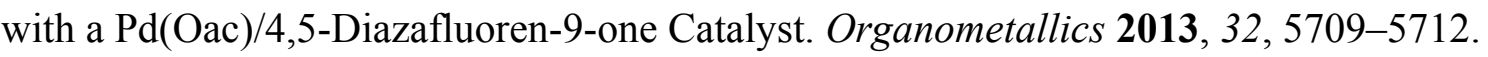


(20) Wang, Z.; Li, X.; Huang, Y. Direct $\alpha$-Vinylidenation of Aldehydes and Subsequent Cascade: Gold and Amine Catalysts Work Synergistically. Angew. Chem. 2013, 125, 1446914473; Angew. Chem. Int. Ed. 2013, 52, 14219-14223.

(21) Weinstein, A. B.; Stahl, S. S. Palladium catalyzed aryl C-H amination with $\mathrm{O}_{2}$ via in situ formation of peroxide-based oxidant(s) from dioxane. Catal. Sci. Technol. 2014, 4, 43014307.

(22) Wang, Z.; Li, L.; Huang, Y. A General Synthesis of Ynones from Aldehydes via Oxidative $\mathrm{C}-\mathrm{C}$ bond Cleavage under Aerobic Conditions. J. Am. Chem. Soc. 2014, 136, 1223312236.

(23) Shao, S.; Zhu, Y.-L.; Ma, K.-R.; Zhao, H.-C.; Qiu, Y.-Q. Two M(II)-1,5-NDS-dafo supramolecular architectures $(\mathrm{M}=\mathrm{Cu}, \mathrm{Cd})$ : syntheses, structures, and photoluminescence properties. J. Coord. Chem. 2013, 66, 2702-2711.

(24) Li, W.-J.; Liu, B.; Qian, Y.; Xie, L.-H.; Wang, J.; Li, S.-B.; Huang, W. Synthesis and characterization of diazafluorene-based oligofluorenes and polyfluorene. Polym. Chem. 2013, 4, 1796-1802.

(25) Ocakoglu, K.; Harputlu, E.; Guloglu, P.; Erten-Ela, S. Design and synthesis of heteroleptic ruthenium (II) complexes and their applications in nanocrystalline $\mathrm{TiO}_{2}$ solar cells. Inorg. Chem. Commun. 2012, 24, 118-24.

(26) Heuer, W. B.; Xia, H.-L.; Abrahamsson, M.; Zhou, Z.; Ardo, S.; Narducci Sarjeant, A. A.; Meyer, G. J. Reaction of $\mathrm{Ru}^{\mathrm{II}}$ Diazafluorenone Compound with Nanocrystalline $\mathrm{TiO}_{2}$ Thin Film. Inorg. Chem. 2010, 49, 7726-7734.

(27) Li, W.-J.; Wu, H.-M.; Li, Y.-B.; Hu, C.-P.; Yi, M.-D.; Xie, L.-H.; Chen, L.; Zhao, J.F.; Zhao, X.-H.; Shi, N.-E.; Qian, Y.; Wang, C.; Wei, W.; Huang, W. Facile synthesis and self-assembly of diazafluorenone-based $p-n$ (donor-acceptor) organic semiconductors. Tetrahedron 2012, 68, 8216-8221. 
(28) Figueirinhas, J. L.; Dong, R. Y. NMR of bent-core nematogens: a mini-review. Magn. Reson. Chem. 2014, 52, 614-624.

(29) Lin, T.-C.; Nemitz, I. R.; McGrath, C. J.; Schubert, C. P. J.; Yokoyama, H.; Lemieux, R. P.; Rosenblatt, C. Nematic molecular core flexibility and chiral induction. Phys. Rev. E 2013, $88,042501 / 1-042501 / 5$.

(30) Yoon, H.; Kang, S.-W.; Lehmann, M.; Park, J. O.; Srinivasarao, M.; Kumar, S. Homogeneous and homeotropic alignment of bent-core uniaxial and biaxial nematic liquid crystals. Soft Matter 2011, 7, 8770-8775.

(31) Lehmann, M.; Köhn, C.; Figueirinhas, J. L.; Feio, G.; Cruz, C.; Dong, R. Y. Biaxial Nematic Mesophases from Shape-Persistent Mesogens with a Fluorenone Bending Unit. Chem. Eur. J. 2010, 16, 8275-8279.

(32) Lehmann, M.; Kang, S.-W.; Köhn, C.; Haseloh, S.; Kolb, U.; Schollmeyer, D.; Wang, Q.; Kumar, S. Shape-persistent V-shaped mesogens-formation of nematic phases with biaxial order. J. Mater. Chem. 2006, 16, 4326-4334.

(33) Chi, C.; Im, C.; Enkelmann, V.; Ziegler, A.; Lieser, G.; Wegner, G. Monodisperse Oligofluorenes with Keto Defect as Models to Investigate the Origin of Green Emission From Polyfluorenes: Synthesis, Self-Assembly, and Photophysical Properties. Chem. Eur. J. 2005, $11,6833-6845$.

(34) Lehmann, M.; Levin, J. Rigid Phenylene Ethynylene Units Linked by a V-Spaped Centre. An Approach to Biaxial Nematogens? Mol. Cryst. Liq. Cryst. 2004, 411, 1315-1323.

(35) Percec, V.; Glodde, M.; Bera, T. K.; Miura, Y.; Shiyanovskaya, I.; Singer, K. D.; Balagurusamy, V. S. K.; Heiney, P. A.; Schnell, I.; Rapp, A.; Spiess, H.-W.; Hudson, S. D.; Duan, H. Self-organization of supramolecular helical dendrimers into complex electronic materials. Nature 2002, 419, 384-387. 
(36) Takatoh, K.; Sakamoto, M. Formation and Properties of Ferroelectric Liquid Crystalline Compound Containing -C(O)-S-O- Linkage. Bull. Chem. Soc. Jpn. 1991, 64, 27202723.

(37) Takatoh, K.; Sakamoto, M. Liquid Crystalline Derivatives Containing Fluorene and Fluorenone Structures. Mol. Cryst. Liq. Cryst. 1990, 182B, 339-349.

(38) Takatoh, K.; Sunohara, K.; Sakamoto, M. Mesophase Transition of Series Materials Containing Fluorene, Fluorenone and Biphenyl Structures with Chiral End Groups. Mol. Cryst. Liq. Cryst. 1988, 164, 167-178.

(39) Okamoto, K.; Nakajima, S.; Itaya, A.; Kusabayashi, S. Charge-carrier Transport in Nematic 2-(p-Decyloxybenzylideneamino)-9-Fluorenone. Bull. Chem. Soc. Jpn. 1983, 56, $3545-3548$.

(40) Okamoto, K.; Nakajima, S.; Ueda, M.; Itaya, A.; Kusabayashi, S. Electrical Dark- and Photo-conductivities of 2-(p-Decyloxybenzilideneamino)-9-fluorenone in the Nematic State. Bull. Chem. Soc. Jpn. 1983, 56, 3830-3832.

(41) Hardouin, F.; Sigaud, G.; Achard, M. F.; Gasparoux, H. Experimental tricritical point nematic-smectic A in a two components-system. Solid State Commun. 1977, 22, 343-345.

(42) Hu, Y.; Miao, K.; Xu, L.; Miao, X.; Deng, W. One Chain Fixed, One Chain Modified by $-\mathrm{C}_{5} \mathrm{H}_{10}-$ : An Efficient Strategy on Fabricating Structural Diversity for 2D Self-Assembly. J. Phys. Chem. C 2017, 121, 21449-21460.

(43) Hu, Y.; Miao, K.; Xu, L.; Zha, B.; Long, M.; Miao, X.; Deng, W. Two side chains, three supramolecules: exploration of fluorenone derivatives towards crystal engineering. Phys. Chem. Chem. Phys. 2017, 19, 19205-19216.

(44) Tai, Z.; Qian, X.; Zou, J.; Xiao, S.; Zhang, F. Molecular assemblies of diazafluorenone Schiff-base amphiphiles. II. The vesicle and its molecular aggregation behavior. Mol. Eng. 1994, 3, 293-299. 
(45) Tzalis, D.; Tor, Y.; Failla, S.; Siegel, J. S. Simple one-step synthesis of 3-bromo- and 3,8-dibromo-1,10-phenanthroline: Fundamental building blocks in the design of metal chelates. Tetrahedron Lett. 1995, 36, 3489-3490.

(46) Manna, K.; Zhang, T.; Greene, F. X.; Lin, W. Bipyridine- and Phenanthroline-Based Metal-Organic Frameworks for Highly Efficient and Tandem Catalytic Organic Transformations via Directed C-H Activation. J. Am. Chem. Soc. 2015, 137, 2665-2673.

(47) Saitoh, Y.; Koizumi, T.; Osakada, K.; Yamamoto, T. Preparation of symmetric dibromides of 1,10-phenanthroline. Can. J. Chem. 1997, 75, 1336-1339.

(48) Wöhrle, T.; Beardsworth, S. J.; Schilling, C.; Baro, A.; Giesselmann, F.; Laschat, S. Columnar propeller-like 1,3,5-triphenylbenzenes: the missing link of shape-persistent hekates. Soft Matter 2016, 12, 3730-3736.

(49) Shi, J.; Wang, Y.; Xiao, M.; Zhong, P.; Liu, Y.; Tan, H.; Zhu, M.; Zhu, W. Luminescent metallomesogens based on platinum complex containing triphenylene unit. Tetrahedron 2015, 71, 463-469.

(50) Wöhrle, T.; Kirres, J.; Kaller, M.; Mansueto, M.; Tussetschläger, S.; Laschat, S. Pushing Steric Bias in the Scholl Reaction to Access Liquid Crystalline Crown Ethers. J. Org. Chem. 2014, 79, 10143-10152.

(51) Tanabe, K.; Suzui, Y.; Hasegawa, M.; Kato, T. Full-Color Tunable Photoluminescent Ionic Liquid Crystals Based on Tripodal Pyridinium, Pyrimidinium, and Quinolinium Salts. $J$. Am. Chem. Soc. 2012, 134, 5652-5661.

(52) Wang, Y.; Liu, Y.; Luo, J.; Qi, H.; Li, X.; Nin, M.; Liu, M.; Shi, D.; Zhu, W.; Cao, Y. Metallomesogens based on platinum(II) complexes: synthesis, luminescence and polarized emission. Dalton Trans. 2011, 40, 5046-5051.

(53) Yasuda, T.; Shimizu, T.; Liu, F.; Ungar, G.; Kato, T. Electro-Functional Octupolar $\pi$ Conjugated Columnar Liquid Crystals. J. Am. Chem. Soc. 2011, 133, 13437-13444. 
(54) Zhao, B.; Liu, B.; Peng, R. Q.; Zhang, K.; Lim, K. A.; Luo, J.; Shao, J.; Ho, P. K. H.; Chi, C.; Wu, J. New Discotic Mesogens Based on Triphenylene-Fused Triazatruxenes: Synthesis, Physical Properties, and Self-Assembly. Chem. Mater. 2010, 22, 435-449.

(55) Huang, W.; Su, L.; Bo, Z. Hyperbranched Polymers with a Degree of Branching of 100\% Prepared by Catalyst Transfer Suzuki-Miyaura Polycondensation. J. Am. Chem. Soc. 2009, 131, 10348-10349.

(56) Sánchez, I.; Núñez, C.; Campo, J. A.; Torres, M. R.; Cano, M.; Lodeiro, C. Polycatenar unsymmetrical $\beta$-diketonate ligands as a useful tool to induce columnar mesomorphism on highly luminescent boron difluoride complexes. J. Mater. Chem. C 2014, 2, 9653-9665.

(57) Wei, B.; Tan, S.; Liang, T.; Cao, S.; Wu, Y. Synthesis, structural and electrochemical characterization of benzimidazole compounds exhibiting a smectic C liquid crystal phase. $J$. Mol. Struct. 2017, 1133, 392-397.

(58) Mills, J. T.; Gleeson, H. F.; Goodby, J. W.; Hird, M.; Seed, A.; Styring, P. X-ray and optical studies of the tilted phases of materials exhibiting antiferroelectric, ferrielectric and ferroelectric mesophases. J. Mater. Chem. 1998, 8, 2385-2390.

(59) Novotná, V.; Hamplová, V.; Kašpar, M.; Podoliak, N.; Bubnov, A.; Glogarová, M.; Nonnenmacher, D.: Giesselmann, F. The effect of lactate unit number in compounds with azo group in the molecular core. Liq. Cryst. 2011, 38, 649-655.

(60) Rössle, M.; Zentel, R.; Lagerwall, J. P. F.; Giesselmann, F. Ferroelectric polysiloxane liquid crystals with 'de Vries'-type smectic $A^{*}-$-smectic $C^{*}$ transitions. Liq. Cryst. 2004, 31, 883-887.

(61) Ovalle, S.; Westphal, E.; Gallardo, H. Ionic liquid crystals with 1,2,3-triazole + tolane core and a pendant imidazolium unit: mesophases from one- to three-dimensional molecular organisation by the variation of alkoxy chains number and spacer length, Liq. Cryst. 2018, 45, $942-952$. 
(62) Godbert, N.; Crispini, A.; Ghedini, M.; Carini, M.; Chiaravalloti, F.; Ferrise, A. LCDiXRay: a user-friendly program for powder diffraction indexing of columnar liquid crystals. J. Appl. Cryst. 2014, 47, 668-679.

(63) Shimogaki, T.; Dei, S.; Ohta, K.; Matsumoto, A. Columnar mesophases constructed by hierarchical self-organization of rod-like diacetylene molecules. J. Mater. Chem. 2011, 21, $10730-10737$.

(64) Wu, S.-H.; Chen, H.-H. Self-assembling behavior of binary mixture of hexa-perihexabenzocoronene derivatives with different molecular symmetry. Tetrahedron 2019, 75, $220-229$.

(65) Bader, K.; Neidhardt, M. M.; Wöhrle, T.; Forschner, R.; Baro, A.; Giesselmann, F.; Laschat, S. Amino acid/crown ether hybrid materials: how charge affects liquid crystalline self-assembly. Soft Matter 2017, 13, 8379-8391.

(66) Li, K.-T.; Lai, C. K. Phase crossover in columnar tris-(1,3,4-oxadiazoles) with pendant quinoxalines. Tetrahedron 2016, 72, 7579-7588.

(67) Girotto, E.; Ferreira, M.; Sarkar, P.; Bentaleb, A.; Hillard, E. A.; Gallardo, H.; Durola, F.; Bock, H. Plank-Shaped Column-Forming Mesogens with Substituents on One Side Only. Chem. Eur. J. 2015, 21, 7603-7610.

(68) Percec, V.; Imam, M. R.; Peterca, M.; Cho, W.-D.; Heiney, P. A. Self-Assembling Dendronized Dendrimers. Isr. J. Chem. 2009, 49, 55-70.

(69) Barberá, J.; Esteruelas, M. A.; Levelut, A. M.; Oro, L. A.; Serrano, J. L.; Sola, E. Rectangular and Hexagonal Columnar Mesophases in Dinuclear Rhodium(II) (Alkyloxy)benzoate Complexes. Inorg. Chem. 1992, 31, 732-737.

(70) Pathak, S. K.; Pradhan, B.; Gupta, M.; Pal, S. K.; Sudhakar, A. A. Liquid-Crystalline Star-Shaped Supergelator Exhibiting Aggregation-Induced Blue Light Emission. Langmuir 2016, 32, 9301-9312. 
(71) Varshney, S. K.; Nagayama, H.; Prasad, V.; Takezoe, H. Room temperature columnar phase: Influence of 2-ethylhexane peripheral chain on the mesomorphism of polyalkynylbenzene-based disc-shaped molecules. Liq. Cryst. 2011, 38, 1321-1329.

(72) Kannan, R.; Sen, T.; Poupko, R.; Luz, Z.; Zimmermann, H. Dynamics and Ordering in the Columnar Mesophases of Octa-alkyloxy Orthocylophane: A Carbon-13 NMR Investigation. J. Phys. Chem. B 2003, 107, 13033-13043.

(73) (a) Cienega-Cacerez, O.; Moreno-Razo, J. A.; Díaz-Herrera, E.; Sambriski, E. J. Phase equilibria, fluid structure, and diffusivity of a discotic liquid crystal. Soft Matter 2014, 10, $3171-3182$.

(74) Ghose, D., Bose, T. R.; Mukherjee, C. D.; Roy, M. K.; Sana, M. A Molecular Mean Field Model for a Rectangular to Hexagonal Phase Transitionin Discotic Liquid Crystals. Mol. Cryst. Liq. Cryst. 1989, 173, 17-29.

(75) Sun, Y. F.; Swift, J. Orientational order and phase transitions in columnar liquid crystals. Phys. Rev. A 1986, 33, 2735-2739.

(76) Haase, W.; Kilian, D.; Athanassopoulou, M. A.; Knawby, D.; Swager, T. M.; Wróbel, S. Enhanced conductivity and dielectric absorption in discotic liquid crystalline columnar phases of a vanadyl complex. Liq. Cryst. 2002, 29, 133-139.

(77) Lehmann, M.; Köhn, C.; Meier, H.; Renker, S.; Oehlhof, A. Supramolecular order of stilbenoid dendrons: importance of weak interactions. J. Mater. Chem. 2006, 16, 441-451

(78) Percec, V.; Mitchell, C. M.; Cho, W.-D.; Uchida, S.; Glodde, M.; Ungar, G.; Zeng, X.; Liu, Y.; Balagurusamy, V. S. K.; Heiney, P. A. Designing Libraries of First Generation $\mathrm{AB}_{3}$ and $\mathrm{AB}_{2}$ Self-Assembling Dendrons via the Primary Structure Generated from Combinations of $(\mathrm{AB})_{y}-\mathrm{AB}_{3}$ and $(\mathrm{AB})_{y}-\mathrm{AB}_{2}$ Building Blocks. J. Am. Chem. Soc. 2004, 126, 6078-6094.

(79) Nguyen, M. L.; Kim, H.-J.; Cho, B.-K. Peripheral chain length-dependent complex phase behaviour in $C_{3}$-symmetric hexa-alkylated liquid crystals. Liq. Cryst. 2018, 45, 1196 1209. 
(80) Pathak, S. K.; Nath, S.; Gupta, R. K.; Rao, D. S.; Prasad, S. K.; Achalkumar, A. S. Effect of regioisomerism on the self-assembly and photophysical behavior of 1,3,4-thiadiazole-based polycatenars. J. Mater. Chem. C 2015, 3, 8166-8182.

(81) Veerabhadraswamy, B. N.; Dambal, H. K.; Rao, D. S. S.; Yelamaggad, C. V. s-Triazine-Based Functional Discotic Liquid Crystals: Synthesis, Mesomorphism and Photoluminescence. ChemPhysChem 2016, 17, 2225-2237.

(82) Tang, J.; Huang, R.; Gao, H.; Cheng, X.; Prehm, M.; Tschierske, C. Columnar mesophases of luminescent polycatenar liquid crystals incorporating a 1,3-substituted benzene ring interconnecting two 1,3,4-oxadiazoles. RSC Adv. 2012, 2, 2842-2847.

(83) Mu, B.; Chen, K.; Chen, J.; Fang, J.; Chen, D. Toward well-organised ionic discotic liquid crystals via versatile supramolecular approach. Liq. Cryst. 2018, 45, 1287-293.

(84) Iehl, J.; Nguyen, T. L. A.; Frein, S.; Hahn, U.; Barberá, J.; Nierengarten, J.-F.;

Deschenaux, R. Designing liquid-crystalline dendronised hexa-adducts of [60]fullerene via click chemistry. Liq. Cryst. 2017, 44, 1852-1860.

(85) Beltrán, E.; Serrano, J. L.; Sierra, T.; Giménez, R. Tris(triazolyl)triazine via ClickChemistry: $\mathrm{A} C_{3}$ Electron-Deficient Core with Liquid Crystalline and Luminescent Properties. Org. Lett. 2010, 12, 1404-1407.

(86) Beltrán, E.; Cavero, E.; Barberá, J.; Serrano, J. L.; Elduque, A.; Giménez, R. Self-Assembly in Helical Columnar Mesophases and Luminescence of Chiral 1H-Pyrazoles. Chem. Eur. J. 2009, 15, 9017-9023.

(87) Software Avogadro, Version 1.1.1, for details see: Hanwell, M. D.; Curtis, D. E.; Lonie, D. C.; Vandermeersch, T.; Zurek, E.; Hutchison, G. R. Avogadro: an advanced semantic chemical editor, visualization, and analysis platform. J. Cheminf. 2012, 4, 17.

(88) Zou, G.; Luo, K.; Zhao, L.; Ni, H.; Wang, H.; Li, Q. Ortho-platinated metallomesogens based on rod mesogenic unit of 2-phenylpyridine derivatives: synthesis, high linearly polarised and phase-state-dependent luminescence. Liq. Cryst. 2018, 45, 593-606. 
(89) Alves, C. M. A.; Naik, S.; Coutinho, P. J. G.; Goncalves, M. S. T. Novel long alkyl side chain benzo $[a]$ phenoxazinium chlorides: synthesis, photophysical behaviour and DNA interaction. Tetrahedron 2009, 65, 10441-10452.

(90) Atkins, P. W.; de Paula, J. Physikalische Chemie; Wiley-VCH: Weinheim, 2013.

(91) It should be noted that solid state photoluminescence spectra were determined after temperature equilibration.

(92) See for an example: Garoff, S.; Meyer, R. B. Electroclinic effect at the A-C phase change in a chiral smectic liquid crysta. Phys. Rev. A: At., Mol., Opt. Phys. 1979, 19, 338347.

(93) Shibahara, S; Takanishi, Y; Yamamoto, J.; Ogasawara, T.; Ishikawa, K.; Yokoyama, H.; Takezoe, H. Observation of a pretransitional effect near a virtual smectic-A-smectic-C* transition. Phys. Rev. E 2001, 63, 062701/1-062701/4.

(94) Qi, A.; Tang, B. Z. Aggregation-Induced Emission: Fundamentals and Applications, Volumes 1, 2, John Wiley \& Sons, Chichester, 2013.

(95) He, Z.; Ke, C.; Tang, B. Z. Journey of Aggregation-Induced Emission Research, ACS Omega 2018, 3, 3267-3277.

(96) We are grateful to one reviewer pointing this out.

(97) Ester, D. F.; Williams, V. E. Molecular symmetry effects on the stability of highly ordered smectic phases. Soft Matter 2018, doi: 10.1080/02678292.2018.1471746. 
For Table of Contents Use Only

\section{Novel Luminescent Diazafluorenone Liquid Crystals}

Korinna Bader, Rafet Gündemir, Wolfgang Frey, Philipp Ehni, Yann Molard, Angelika Baro, and Sabine Laschat*

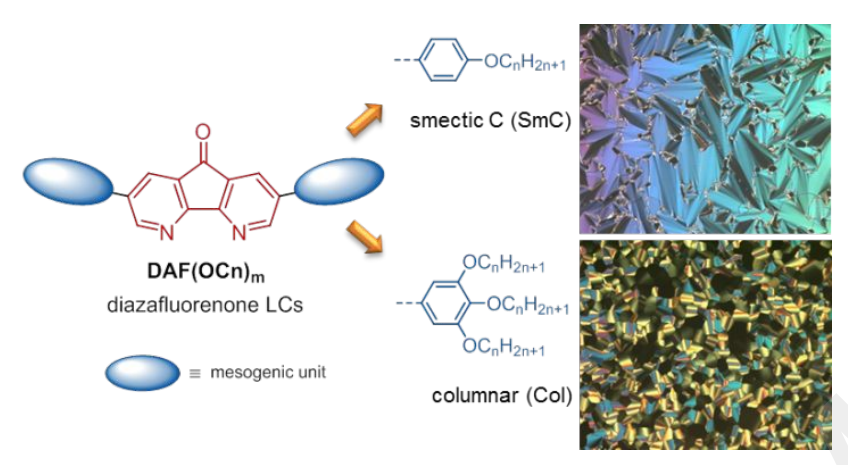

Liquid crystalline properties of 2,7-diphenyl-4,5-diazafluorenones carrying 2, 4 or 6 peripheral alkoxy side chains depend on both the number of side chains and their lengths.

Crystal structure data of a series of rod-shaped diazafluorenones helped to rationalize their self-assembly and to understand geometry and thermal stability. Temperature-dependent luminescence revealed aggregation-induced emission (AIE) depending on the supramolecular order of the bulk phase. 